\title{
A trade-off in corporate diversification
}

\author{
Manapol Ekkayokkaya \\ Faculty of Commerce and Accountancy \\ Chulalongkorn University \\ Bangkok, Thailand \\ Manapol@cbs.chula.ac.th \\ Krishna Paudyal \\ Department of Accounting and Finance \\ University of Strathclyde \\ Glasgow, United Kingdom \\ Krishna.paudyal@strath.ac.uk
}

We are grateful for valuable comments and suggestions from seminar participants at the Chulalongkorn Accounting and Finance Symposium, Leeds University Business School, University of Strathclyde, Chulalongkorn Business School, Singapore Management University Summer Camp, FMA European Conference, Luxembourg School of Finance, Centre for Corporate Governance at Copenhagen Business School, SKEMA (Lille), Thammasat Business School and especially the discussants (Paul Malatesta; Theo Vermaelen; Reddi Kotha; Bill Megginson), Efraim Benmelech, Hank Bessembinder, Anchada Charoenrook, Anant Chiarawongse, Tom Connelly, Paul Draper, Joseph Fan, David Hillier, Phil Holmes, Harrison Hong, Anya Khanthavit, Arnat Leemakdej, Clive Lennox, Ron Masulis, Pantisa Pavabutr, David Reeb, Sira Suchintabandid, Steen Thomsen, Wolf Wagner, Thaisiri Watewai, and Christian Wolff. All remaining errors are ours. Manapol Ekkayokkaya acknowledges research grants from the Chulalongkorn University Centenary Academic Development Project and the Faculty of Commerce and Accountancy, Chulalongkorn University.

Corresponding author: Manapol Ekkayokkaya, Department of Banking and Finance, Faculty of Commerce and Accountancy, Chulalongkorn University, Bangkok 10330, Thailand. Tel: +66 2185671; Fax: +66 2 2185676; Email: Manapol@cbs.chula.ac.th

This draft: July 19, 2015

\section{ALL COMMENTS MOST WELCOME}




\title{
A trade-off in corporate diversification
}

\begin{abstract}
The marginal benefits of diversification exceed the costs by a decreasing margin, and diversifying beyond the optimal level will produce a wealth loss. This trade-off predicts an inverted U-relation between the degree of diversification and wealth. We find empirical evidence in support of this trade-off proposition. Consistent with the tradeoff, firms diversify cautiously and stop diversifying before the marginal benefits are offset by the costs. Our findings lend support to the arguments suggesting efficient diversification. In line with the endogeneity of diversification, the findings also indicate that the optimal level of diversification can vary across firms depending on their reasons for diversifying.
\end{abstract}

Key words: Corporate diversification, benefits and costs of diversification, non-linear wealth effect, acquisitions

JEL Classification: G31; G32; G34 


\section{Introduction}

The benefits and costs of corporate diversification are well studied. Yet, the value of, i.e., the net gain from, diversification remains a largely unsettled debate. ${ }^{1}$ As Stein (2003, p. 145) notes, "after all, taken as a whole, the theoretical work does not lead to a clear-cut prediction that diversification ... is on average good or bad". In a similar vein, Hadlock et al. (2001, p. 614) point out that when trying to understand the value of diversification, it is important to "identify when the costs are likely to exceed the benefits, and vice versa". We seek to contribute to this fundamental research agenda. While offering a variety of important insights, numerous studies, when viewed together, point to the possibility that the benefits and costs of diversification vary with the degree of diversification. Specifically, at low degrees of diversification the marginal benefits of diversification exceed the costs yielding, a wealth increase. The wealth increase becomes smaller as firms diversify further, and turns into a wealth loss once firms diversify beyond an optimal level. Beyond the optimum, the increasingly large costs exceed the benefits. This cost-benefit trade-off predicts an inverted U-relation between the degree of diversification and shareholder wealth. To our knowledge, this intuitive trade-off proposition appears to remain empirically unexplored.

In examining the trade-off proposition, we employ diversifying acquisitions as a proxy for diversification attempts. Acquisitions are the most common means through which firms diversify (e.g., Graham et al., 2002). We measure the wealth change due to a

\footnotetext{
1 The conglomerate discount widely reported in earlier studies (e.g., Lang and Stulz, 1994) has been challenged by recent evidence. Several recent studies report that the discount is attributable to the choice of methodology (e.g., Campa and Kedia, 2002) or fundamental factors other than diversification itself (e.g., Graham et al., 2002). There is also growing evidence that internal capital markets are active and can be beneficial to firm performance (e.g., Billett and Mauer, 2003; Duchin, 2010). However, Lamont and Polk (2002) find that an exogenous increase in diversity reduces excess firm value, supporting the view of inefficient internal capital markets. Ozbas and Scharfstein (2010) report that investment in unrelated segments of conglomerates is less responsive to industry investment opportunities than is investment in stand-alone firms, and attribute this inefficiency to agency problems. We review relevant theoretical arguments in section 2. For an insightful review of the literature, see for example, Maksimovic and Phillips (2007).
} 
diversification attempt as the announcement-period excess return to a diversifying acquirer. We find empirical support for the proposition. The predicted inverted Urelation between the degree to which a firm operates in different industrial segments and wealth provides a robust description of when benefits of diversification are likely to exceed the costs, and vice versa. We find that, over a low range of diversification, diversifying acquisitions significantly increase the wealth of acquirer shareholders at a decreasing rate. Shareholders will suffer a wealth loss if firms make a diversifying acquisition, i.e., diversify, beyond the optimal level of diversification.

We also assess whether the inverted U-relation between diversification and wealth we observe is a chance result. If the trade-off proposition is refutable, the inverted U-relation should be unique to increases in firm scope and not increases in firm size. Results show that the inverted U-relation is present only among diversifying acquisitions, and not among non-diversifying acquisitions - either vertically related or focused, indicating refutability of the trade-off prediction.

To further understand the trade-off facing shareholders, we examine the extent to which shareholders gain from optimal diversification and lose from diversifying beyond the optimal level. While recognizing that the optimal level of diversification is likely to vary across individual firms, the empirical estimates imply the optimum of around seven segments for an average diversifying acquirer in the full sample. Notably, $96 \%$ of the sample diversifiers end up with seven or fewer segments following a given diversification attempt. This pattern indicates that firms in general may not diversify beyond an optimal level. Diversifiers that operate below the implied optimal level of diversification before making a diversifying attempt earn a significant announcementperiod gain. The gain also monotonically and significantly falls in diversifiers' existing degree of diversification. Though shrinking by several folds, the gain remains non- 
negative for the small group of diversifiers that already operate at or beyond the implied optimum before diversifying. These gain patterns together with a very small number of firms that diversify beyond the implied optimum are consistent with the view that firms diversify cautiously and stop diversifying before the marginal benefits are offset by the increasing costs.

While these findings are indicative of value creation from efficient diversification, the observation that most diversifiers operate at levels below the implied optimum might be interpreted as firms generally being under-diversified. However, a diversifying decision involves significant costs and is not costlessly reversible (Denis et al., 1997; Gomes and Livdan, 2004). Such irreversibility gives firms a disincentive to diversify to the optimal level in a given attempt. Thus, the observation that most diversifiers do not reach the optimal level in a given attempt is consistent with the irreversible nature of the decision to diversify.

The endogenous nature of the decision to diversify implies that our results may reflect some unobservable firm-specific factors that drive firms to diversify rather than the effect of the act of diversification. We address this endogeneity issue in two ways. First, we incorporate firm (acquirer) fixed effects in our regression analyses (e.g., Campa and Kedia, 2002). Despite the inclusion of firm fixed effects, the inverted Urelation remains significant with the estimates also remaining similar in size. Secondly, we investigate how the trade-off may differ across firm types. We find that although firms with expected declines in their current activities benefit from diversification similarly to other firms, the offsetting costs increase significantly faster for the diversifiers with such expected declines. This result lends support to the view that expected poor prospects drive firms to diversify in search for new growth opportunities (e.g., Matsusaka, 2001). Estimates also reveal that diversifiers gain and face similar cost- 
benefit trade-offs, whether their existing operations generate large or small free cash flow. Such similarity is consistent with free cash flow facilitating efficient diversification.

Overall, our findings suggest that diversifying acquisitions on average increase shareholder wealth, albeit at a decreasing rate. This is a sharp contrast to several earlier studies of conglomerate acquisitions, which report small announcement-period losses to the acquirers (e.g., Morck et al., 1990; Chevalier, 2004). Here, one might view the earlier evidence as invalidating the trade-off proposition. Considering the difference in sample composition between earlier studies and ours, an alternative possibility is that the deviation is attributable to our use of acquirer gains as a proxy for gains from diversification attempts. Acquirer gains are likely to be a noisy measure of synergy when acquirers have weak bargaining power against targets. Acquirers' bargaining power is relatively weak when targets are publicly traded firms, but strong when targets lack ready access to the capital market and liquidity, i.e., when targets are unlisted firms (Officer, 2007). While earlier studies typically cover only acquisitions of publicly trade targets, $86 \%$ of our much more comprehensive sample involves unlisted targets. Thus, acquirer gains in our analysis should adequately reflect the synergistic gains. Consistent with this possibility, diversifier gains are significant and the inverted U-relation is observable only when targets are unlisted firms. Similar to prior studies, our sample diversifiers suffer small losses when acquiring publicly traded targets. However, the combined gains to diversifiers and their publicly traded targets are significant. The significant combined gains are consistent with the implication from our main analysis of acquirer gains that diversifying acquisitions generally increase shareholder wealth.

The benefits and costs of diversification are well established, and the idea that firms weigh the benefits against costs before deciding to diversify is not unheard of. Our 
study can be viewed as building on the existing insights by proposing that the benefits and costs of diversification change with the degree to which firms diversify such that there is an optimal level of diversification, and by providing empirical evidence on this proposition. Accordingly, our analysis addresses the fundamental issue of when the benefits of diversification are likely to exceed the costs, and vice versa. Our study also extends the literature that examines the average value of diversification. The evidence in our study indicates that firms that diversify do so cautiously and optimally, in line with diversification being an efficient corporate strategy. This evidence corroborates the findings of Hann et al. (2013) that diversified firms enjoy a lower cost of capital than comparable focused firms, as well as the recent studies reporting evidence of active and efficient internal capital markets (e.g., Duchin, 2010). As noted by Maksimovic and Phillips (2007), over 50\% of production in the U.S. economy is delivered by conglomerates. Our evidence, along with several recent studies, also serves as a plausible rationale for the large prevalence of conglomerates in the U.S. economy.

In the next section, we review the existing theoretical insights, and discuss the trade-off proposition and its empirical prediction. In section 3, we describe our empirical design and data. Empirical results are reported and discussed in section 4 . Section 5 concludes our study.

\section{A trade-off in corporate diversification}

Building on the existing insights, we propose that at low levels of diversification the marginal benefits of diversification exceed the costs at a decreasing rate, and beyond the optimal level of diversification the costs exceed the benefits by an increasing margin. In this section, we review the benefits and costs of diversification, and discuss a testable prediction of the trade-off proposition. 
Coinsurance of corporate debt and the resulting increase in borrowing capacity provide financial rationale for diversification (e.g., Lewellen, 1971). Fluck and Lynch (1999) show that, through such risk reduction, diversification allows firms to obtain financing for their marginally profitable projects to survive a period of distress and subsequently improve in profitability. To the extent that coinsurance alleviates countercyclical deadweight losses such as costly external finance and investment distortions during economic downturns, diversification can reduce firms' systematic risk and cost of capital (Hann et al., 2013). This form of financial synergy is in line with efficient resource allocation in an internal capital market. By becoming multi-segment thereby creating an internal capital market, firms can bypass the external capital market frictions and achieve more efficient investment decisions (e.g., Stein, 1997). Diversification can also improve access to the external capital market by alleviating the adverse selection problem typically facing single-segment firms (Hadlock et al., 2001). ${ }^{2}$

While sharing of corporate resources is a key benefit of within-segment or focused expansion, multi-segment firms can also benefit from scope economies. In the presence of a comparative advantage in terms of capabilities, value creation can arise from application of fungible knowhow and tacit knowledge across different products as common production input (Teece, 1982). Elimination of redundancies across different activities permits savings on the aggregate fixed cost of production (Gomes and Livdan, 2004).

The operating-side and financial-side benefits are not mutually exclusive and should be complementary. Regardless of trading frictions, they require common ownership and cannot be replicated by individual investors. Without offsetting costs,

\footnotetext{
${ }^{2}$ Assuming imperfectly correlated valuation errors across different industrial segments, the magnitude of underpricing of the overall firm due to adverse selection should be smaller for a multi-segment firm than for a single-segment firm. Hadlock et al. (2001) find evidence in support of this hypothesis.
} 
the benefits would lead to shareholder wealth strictly increasing in the degree of diversification. Prominently, the existing insights commonly characterize diversification benefits as material for single-segment firms. This is consistent with the law of diminishing marginal return, which implies that the benefits are larger for singlesegment firms and become smaller for firms that already operate in multiple segments. Holding constant available assets in an economy, for instance, the amount of marginal coinsurance and internal resource allocation should be larger for single-segment firms than for firms that already hold uncorrelated assets. In the trade-off proposition, we therefore assume decreasing marginal benefits. Curve ABE in Figure 1 depicts the marginal benefits of diversification that strictly increase at a decreasing rate.

Another strand of the literature suggests that the conglomerate form of organization has significant costs and destroys shareholder wealth. Due to bounded rationality as in March and Simon (1958), diversifying intensively can inflict constraints on headquarters' cognitive ability in coordination and resource allocation. ${ }^{3}$ In relation to scope economies, as Teece (1982) points out, a large degree of diversification gives rise to bottlenecks in accessing the common input. Similarly, increasing the degree of diversification increases the probability of uncorrelated project evaluation errors, which in turn leads to errors in resource allocation by headquarters (Stein, 1997). Stein also shows that such errors do not arise from focused expansion.

The uncorrelated nature of growth prospects of divisions in conglomerates also nurtures agency problems. Scharfstein and Stein (2000) demonstrate inefficient crosssubsidies in conglomerates due to headquarters' attempt to curb rent-seeking by divisional managers. They also show that the likelihood of such inefficiencies becomes

\footnotetext{
${ }^{3}$ Due to reliance on the services provided by the existing managerial group, hiring more managers does not give a solution in the short run (Penrose, 1959).
} 
greater when the difference in investment opportunities among divisions is large. In a setting where divisional surpluses are up for grabs by other divisions, Rajan et al. (2000) show that the disincentives to make optimal investments facing large-growth divisions can lead to inefficient cross-subsidization, and this problem is most severe in a conglomerate with largest diversity.

One common feature of the theories demonstrating the costs of diversification reviewed above is that the probability of inefficiencies increases as conglomerates become more diversified. Holding constant the costs of such inefficiencies to shareholders, this feature implies that the expected marginal costs of diversification become larger as multi-segment firms pursue further diversification. It is also possible that the costs of inefficiencies increase in the degree of diversification (e.g., Rajan et al., 2000). Through either of these mechanisms or both, we therefore assume increasing marginal costs of diversification as depicted by curve CG in Figure 1. Diversification costs become material once firms diversify to some degree (point $d_{a}$ ). As firms diversify further, diversification costs become larger producing an increasingly large counterweight to the marginal benefits.

The existing insights are formulated to shed light on different aspects of corporate diversification. Taken in isolation, theories demonstrating benefits and theories demonstrating costs of diversification might be viewed as making conflicting predictions. We propose that, when viewed together, the two strands of existing insights jointly imply that the marginal wealth effect of diversification is dominated by the benefits at low levels of diversification, and by the increasingly large offsetting costs at high levels of diversification. Curve ABDF in figure 1 illustrates this trade-off. Diversification yields a decreasing wealth gain up to point $d_{b}$, i.e., the optimal level of diversification. Beyond point $d_{b}$, the increasingly large costs more than offset the 
marginal benefits, leading to an increasing wealth loss as depicted by the downward sloping contour DF. Thus, the trade-off proposition predicts an inverted U-relation between the degree to which a firm operates in different industrial sectors and shareholder wealth.

On the surface, the upward slope of contour ABD would imply that all firms should find it optimal to diversify at least on some small scale. We note that the tradeoff analyzed in Figure 1 involves the benefits and costs associated with the decision to diversify. Thus, firms may choose to stay focused if the net gain from diversification is smaller than the net gain from focusing (e.g., Matsusaka, 2001). In other words, some firms may choose to not diversify even if the decision to diversify would lie to the left of point $d_{b}$, i.e., in and of itself offer positive NPV to shareholders. Given that the marginal benefits and costs of diversification facing firms are known to their managers, more interestingly, one would expect that wealth-maximizing firms on average carefully diversify and stop diversifying before their shareholders suffer a wealth loss. For at least two broad reasons, however, firms may diversify beyond point $d_{b}$ despite the resulting wealth loss. First, diversification allows managers to reduce their employment risk (e.g., Amihud and Lev, 1981). Second, managers derive private benefits, e.g., entrenchment, from diversification (e.g., Shleifer and Vishny, 1989; Denis et al., 1997; also Aggarwal and Samwick, 2003). In addition, inefficient diversification may also result from managers' overconfidence in their ability to extract gain from operating multiple businesses (see Roll, 1986). It is the diversity of assets owned by conglomerates that shelters wasteful investments, due to either managerial objectives or hubris, from the external market discipline.

The literature distinguishes between related and unrelated diversification. We view the trade-off as speaking to unrelated rather than related diversification. The 
benefits of diversification discussed above are unlikely to be of first-order importance to firms pursuing a related integration. For example, the benefits of debt coinsurance or by-passing the external market frictions are unlikely to be economically meaningful for a supplier-customer integration. On the cost side, given that projects along the same supply chain are materially correlated, a related integration should not give rise to uncorrelated project evaluation errors or inefficient cross-subsidization. Therefore, we conjecture that the trade-off prediction does not hold for related diversification. Nevertheless, we empirically address this conjecture in section 4.3.

\section{Empirical design}

The focus of our empirical analysis is to examine whether the trade-off proposition describes the relation between diversification and wealth. In this section, we present our empirical design and the sample used in testing the proposition.

\subsection{Testing the trade-off prediction - the inverted U-relation}

One direct test of the predicted inverted U-relation between the degree of diversification and shareholder wealth in Figure 1 is to observe a change in wealth as a firm diversifies. Since the relation is quadratic and point A can be viewed as the level of wealth in a single-segment firm $\left(W_{s}\right)$, wealth in a multi-segment firm $\left(W_{m}\right)$ can be generally expressed as:

$$
W_{m}=W_{s}+b(d)+c\left(d^{2}\right)
$$

where $d$ is the degree of diversification, and $b$ and $c$ are model parameters (i.e., effect of diversification on wealth). For a single-segment firm, $d=0$. The wealth change $(\Delta W)$ due to a diversification attempt is then the difference between wealth before $\left(W_{m, 0}\right)$ and wealth after $\left(W_{m, 1}\right)$ diversification: 


$$
\Delta W=W_{m, 1}-W_{m, 0}=W_{s}+b\left(d_{1}\right)+c\left(d_{1}^{2}\right)-W_{s}-b\left(d_{0}\right)-c\left(d_{0}^{2}\right),
$$

where $d_{0}$ and $d_{1}$ are the degree of diversification before and after the firm diversifies, respectively. Defining $\delta=d_{1}-d_{0}$, equation (2) becomes:

$$
\Delta W=b(\delta)+c\left(2 d_{0} \delta+\delta^{2}\right) .
$$

For a given diversification attempt, the trade-off proposition predicts that $b$ and $c$ from equation (3) have a positive and negative empirical value, respectively.

To test this prediction, we estimate variants of the regression model in (4):

$$
\Delta W_{i}=\beta_{1}+\beta_{2}\left(\delta_{i}\right)+\beta_{3}\left(2 d_{0, i} \delta_{i}+\delta_{i}^{2}\right)+\varepsilon_{i} .
$$

$\Delta W_{i}$ is the wealth change due to a given diversification attempt by firm $i . d_{0, i}$ is the firm's degree of diversification before diversifying, and $\delta_{i}$ the degree of diversification the firm adds to its corporate portfolio through its diversification attempt. The trade-off proposition predicts a positive sign for $\hat{\beta}_{2}$ and negative sign for $\hat{\beta}_{3}$.

Since acquisitions are the common means through which firms diversify, we estimate equation (4) using diversifying acquisitions as a proxy for diversification attempts. With acquisition data, $\Delta W_{i}$ should ideally be measured as the combined announcement-period gain to the acquirer and target in diversifying acquisition $i$. Similar to other acquisition studies, most (86\%) targets in our sample are unlisted firms. Thus, a feasible measure of $\Delta W_{i}$ for the vast majority of our sample becomes the announcement-period gain to the acquirer. We inevitably adopt this measure. One potential concern with this measure is that acquirer gains incorporate not only the expected synergy (i.e., $\Delta W$ in our context), but also the bargaining power of acquirers against targets. When acquirers have weak bargaining power, their gains are likely to be close to zero as the expected synergistic gain will be allocated mostly to targets. In this setting, acquirer gains would be a noisy measure of $\Delta W$. Acquirer gains will adequately reflect $\Delta W$ if acquirers have material bargaining power, and at least, a material portion 
of the synergistic gain is allocated to them. This latter scenario fits well with our sample composition. A lack of liquidity facing unlisted targets and the discounted acquisition price they receive relative to publicly traded targets indicate that acquirers have material bargaining power when targets are unlisted firms (Officer, 2007). Although we have no means to directly assess the relative bargaining power of acquirers and targets, our results lean towards suggesting that acquirer announcement-period gains in our analysis reasonably reflect of the true value of $\Delta W$. Nevertheless, we further address this issue in section 4.5 .

We estimate announcement-period return as market-adjusted excess return, i.e., acquirer return minus return on the CRSP value-weighted index, over the five-day period $(-2,+2)$ surrounding the announcement date. ${ }^{4}$ We use the market-adjusted model because the conventional methodology (see Brown and Warner, 1985) requires a long pre-event period for estimating the model parameters. As reported below, a large number of our sample firms make a prior acquisition in periods immediately preceding their current acquisition. Hence, a substantial portion of our sample firms lacks a sufficiently long estimation period that is free from the event under analysis. For the same reason, our approach has been adopted by several others (e.g., Fuller et al., 2002). Brown and Warner (1980) show that for short windows, adjusting for the systematic (beta) risk does not improve precision of abnormal return estimates.

\subsubsection{Identifying diversification attempts}

One common way to identify a diversifying, or unrelated, acquisition is to observe a deal in which the acquirer and target have different primary 2-digit SIC codes.

\footnotetext{
${ }^{4}$ For a random sample of 500 deals, Fuller et al. (2002) observe that the announcement dates recorded by the SDC are correct for $92.6 \%$ of the sample. The recorded dates that are inaccurate are off by no more than two days. The $(-2,+2)$ window should therefore capture the announcement effect without causing considerable noise. As reported below, we draw our sample from the SDC.
} 
However, two different 2-digit industries may be related, especially vertically. An acquisition involving firms from different 2-digit industries may be an upstream or downstream integration rather than an attempt to diversify. To address this concern, we define a diversifying acquisition as (i) a deal in which the acquirer and target have different primary 2-digit SIC industries where (ii) the degree of vertical relatedness between the acquirer and target primary industries is no greater than $5 \% .{ }^{5}$ Yet, these criteria allow multi-segment acquirers to have a non-core operation in their target's primary industry or one of its industries, while having a primary industry that is different from their target's primary industry. Acquirers in such deals do not enter a new line of business. Therefore, we additionally require that a diversifying acquisition must also be (iii) a deal in which at least one of the target's industries differs from all of the acquirer's industries.

We calculate a measure of vertical relatedness as in Fan and Lang (2000). ${ }^{6}$ This measure is based on the industry input-output (IO) data provided by the Bureau of Economic Analysis (BEA), using both the SIC and NAICS codes. ${ }^{7}$ Although our $5 \%$ cut-off appears much stricter than the 10\% cut-off in Ozbas and Scharfstein (2010), our cut-off should be viewed as the lower bound of true relatedness. As noted by Fan and Goyal (2006), because the IO data is based on the value of shipments, a relatedness measure

\footnotetext{
${ }^{5}$ We adopt the 2-digit level as the literature suggests that the 3- or 4-digit level is likely to be too detailed to identify the industrial structure of a firm (e.g., Servaes, 1996; Maquieira et al., 1998).

${ }^{6}$ Hoberg and Phillips (2010) propose a text-based measure of relatedness between a pair of firms using product descriptions in the $10-\mathrm{K}$ filings. Thus, this measure is not applicable to acquisitions involving unlisted targets, which are the common means through which firms diversify and make up the vast majority of our sample. Also importantly, Hoberg and Phillips (p. 3784) note that their algorithms "are not able to separate the text associated with each segment of conglomerate firms". Though innovative and useful in several other contexts, their measure is not applicable to tests involving diversifying acquisitions by multi-segment firms in our study.

7 The BEA updates its survey and IO data every five years, and the industry definitions change from update to update. Therefore, in calculating a measure of relatedness for each deal, we match the IO definitions in the 1987 survey to the sample deals made between 1990 and 1991: our sample period begins in 1990. Similarly, the 1992 definitions are matched to deals made between 1992 and 1996, the 1997 definitions to deals made during 1997 and 2001, and so on. The BEA adopts NAICS codes for its 1997 survey onwards. We use SIC codes for matching IO definitions to deals made between 1990 and 1996, and NAICS codes for deals made in 1997 onwards.
} 
would be much larger if it was based on production costs. We nonetheless repeat all of our tests using the $10 \%$ cut-off, and the results (untabulated) are in the same direction though weaker in significance. All of our untabulated results are available on request.

\subsubsection{Measuring the degree of diversification}

The formal test of the trade-off prediction in equation (4) requires empirical estimates of $d_{0, i}$ and $\delta_{i}$ around the bid announcement. Using the number of 2-digit SIC codes (henceforth, segments) is the directly applicable approach. This is because it allows both $d_{0, i}$, and crucially, $\delta_{i}$, to be estimated from actual data around the time of bid announcement. Thus, we use the number of segments of acquirer $i$ observed before the bid announcement as a proxy for $d_{0, i}{ }^{8}$ Our proxy for $\delta_{i}$ is the number of new segments added through an acquisition to the existing segments of acquirer $i$. Thus, $\delta_{i}$ is the number of the target's segments, observed before the bid announcement, that are not the same as any of the acquirer's existing segments.

We recognize that the number of segments is an imperfect measure of diversification as it weights large and small segments equally. This equal-weighting may introduce noise to our diversification measure. However, this is not of serious concern as the effect of such noise would be to bias our analysis away from finding significant results. Alternative to the use of the number of segments is a Herfindahl index, which takes into account segment size. However, using the index would require $\delta_{i}$ to be estimated using annual change in the reported segment data. This is not practical because it is common that firms make multiple acquisitions within a year. As reported

\footnotetext{
${ }^{8}$ In estimating $d_{0, i}$, we do not adjust for vertical relatedness between a pair of segments. Treating two vertically related segments of a firm as one segment would make the estimation of $\delta_{i}$ problematic. When two segments are collapsed into one, it becomes practically infeasible to assign an industry code to the newly bunched segment. As a result, estimation of $\delta_{i}$ would become problematic for acquisitions involving an acquirer or target with a bunched segment. If non-adjustment for vertical relatedness introduces non-trivial noise to our analysis, it will tilt our results towards being insignificant.
} 
in section 3.2, such frequent acquirers are common in our sample. Nevertheless, we repeat the analysis in Table 4 using an asset-based Herfindahl index as a proxy for $d_{0, i}$ with sample partitioning as in Table 2 of Lang and Stulz (1994). The results, reported in Table A.I, exhibit a pattern similar to, though less discernible than, the pattern observed in Table $4 .{ }^{9}$ This suggests that the assumption of equal weights is unlikely to render the use of the number of segments in our application overly noisy.

\subsection{Data and sample}

Our sample is drawn from the completed transactions reported in the Thomson Financial (SDC Platinum) U.S. Mergers and Acquisitions database with the initial bid announced between January 1, 1990 and December 31, 2010. Since the focus of our study is on industrial diversification, we examine only domestic acquisitions. ${ }^{10} \mathrm{We}$ require that the acquiring firm is a publicly traded firm listed on the Center for Research in Security Prices (CRSP) and Compustat files during the period of 11 days before through two days after the announcement date. We also require that acquirers have non-negative total assets. Target firms can be a publicly traded firm, subsidiary company, or privately held entity. To ensure that our sample consists of material transactions that are not transactions to clean up the remaining interests, we further require that (i) the deal value (excluding fees and expenses) is at least $\$ 1$ million and

\footnotetext{
${ }^{9}$ The trade-off predicts that gains to diversifying acquirers $(\Delta W)$ decline in $d_{0, i}$. In both mean and median, Table 4 shows that the gains monotonically decline in the diversifier number of segments. When using the Herfindahl index, such a monotonic pattern is less pronounced for the means, and becomes persistently non-monotonic for the medians. The less discernible pattern associated with the use of the index may be attributable to the noise introduced by multiple acquisitions made within a year. The median results are untabulated.

${ }^{10}$ Acquisitions of foreign targets can be considered international diversification at the corporate level. Although the general tenor of the trade-off proposition is applicable to international diversification, we limit our analysis to domestic acquisitions to make its scope manageable. Examining the proposition in the context of international diversification should yield fruitful future research.
} 
(ii) the acquirer holds less than $50 \%$ of the shares in the target before the bid announcement. A total of 18,460 acquisitions survive these initial sample criteria.

We use the SIC codes reported by the SDC. As pointed out by Kahle and Walkling (1996), SIC codes change over time for many firms, thereby making the codes provided by Compustat, which are the latest codes and ones accessible to researchers, an inaccurate description of the firm's industrial structure in prior years. As noted by Schlingemann et al. (2002), the SIC coding in the SDC may differ from that in Compustat. We check at the 2-digit level and find that the coding is identical between these two sources. We also use the SDC as the source for NAICS codes.

From the initial sample, 5,823 deals involve an acquirer and target from different primary 2-digit industries where the acquirer adds at least one new segment to its corporate portfolio. Out of these 5,823 deals, 3,590 deals meet our 5\% cut-off criterion to qualify as a diversifying acquisition. Among the remaining deals, 3,057 deals have an acquirer and target from different 2-digit industries with vertical relatedness above $5 \%$ (henceforth, vertically related deals), and 10,276 deals involve firms in the same primary 2-digit industry (henceforth, focused deals). ${ }^{11}$ For a large number of deals, data required for estimating free cash flow (an important control variable) is missing. This reduces the number of diversifying deals in our final sample to 3,229 (from 3,590), vertically related deals to 1,944 (from 3,057), and focused deals to 9,890 (from 10,276). ${ }^{12}$ In this final sample, acquirers in 38\% (1,219) of diversifying deals make at least one prior deal within the preceding year. For vertically related and focused deals, this proportion is $41 \%$.

\footnotetext{
${ }^{11}$ In identifying vertically related deals, we do not require a deal to add a new segment to the acquirer. ${ }^{12}$ Although our tabulated results are based on deals with complete data (i.e., the reduced sample), we rerun all of our tests using the larger sample (i.e., omitting free cash flow) and find similar results.
} 
Table 1 reports distributions of the final sample. As shown in Panel A, the number of deals in the full sample fluctuates across years peaking in the second half of 1990s and dropping after 2000, reflecting the wave of the 1990s. The third column reveals that for every five acquisitions one is diversifying, and this proportion is persistent across the sample period. Hence, firms still diversify. The fourth column shows that when firms make an acquisition outside of their core industry, vertical integration (13\%) is much less common than unrelated diversification. Panel A also shows that acquirers earn positive announcement-period excess returns from diversifying (1.99\%), vertically related (1.83\%), or focused $(1.75 \%)$ acquisitions. All of these gains are significant and indistinguishable from each other. Similar to vertically related and focused acquisitions, excess returns from diversifying acquisitions are positive for every year and significant in most years. This result does not lend support to the widely held view that corporate diversification is ex ante inefficient, but appears to suggest that diversification generally enhances wealth and is in line with the observation that firms still diversify.

Panel B describes the distributions of the numbers of segments for diversifying acquisitions in the final sample. Shin and Stulz (1998) categorize firms in their study into single-segment, moderately diversified (two to four segments) and highly diversified (five or more segments) firms. In 35\% $(1,125)$ of the deals, diversifiers are single-segment firms before acquisition. In 57\% (1,831) of the deals, diversifiers are moderately diversified firms. Notably, very few diversifiers (8\%) are highly diversified firms. Most of the targets operate in only one or two segments: 53\% of them are singlesegment firms, and $32 \%$ have two segments. In three quarters of the deals, diversifiers add only one segment to their corporate portfolio, and two segments are added in $20 \%$ of the deals. Following a given diversification attempt, diversifiers in $75 \%$ of the deals 
end up being moderately diversified firms (i.e., operating in four or fewer segments). These statistics suggest that firms appear to diversify cautiously, in line with the gains to diversifiers observed in Panel A.

\subsection{Sample characteristics and control variables}

Because we use acquisitions as a lab for testing the trade-off prediction, we also incorporate into equation (4) as control variables the known determinants of acquirer announcement-period gain (see Moeller et al., 2004). ${ }^{13}$ The predicted inverted Urelation is a function of both $d_{0}$ and $\delta$. Therefore, we present statistics for diversifying acquisitions across different levels of existing diversification and added diversification. We know of no theoretical guidance on how to distinguish between moderately and highly diversified firms, and as a result, divide the sample deals into three groups based on the diversifier pre-acquisition number of segments as in Shin and Stulz (1998). Given the distribution of added segments observed in Panel B of Table 1, we also divide the sample deals into two groups: one segment, and two or more (i.e., multiple) segments added. As reported in Table 2, the variations in firm and deal characteristics are indicative of their potential influence on acquirer gains from diversifying acquisitions.

Moeller et al. (2004) report that acquirer gain varies with acquirer size (book total assets). As shown in Panel A, diversifiers' size monotonically increases, in both mean and median, in the degree to which they are diversified and is larger in deals that add multiple segments. Thus, diversifier size may, at least partially, explain the relation between diversification and wealth. Diversifiers' Tobin's $q$ decreases monotonically in both mean and median, and is smallest for highly diversified acquirers. Diversifiers

\footnotetext{
13 In the interest of parsimony, we refer readers to the insightful literature review and references cited in Moeller et al. (2004). For the definitions of acquirer and deal characteristics, see notes to Table 2.
} 
adding multiple segments also have lower $q$. These $q$ patterns appear in line with the association between diversified firms and low valuation reported in earlier studies (e.g., Lang and Stulz, 1994). The free cash flow hypothesis posits that large free cash flow facilitates empire-building or wasteful investments by managers, and that leverage subjects managers to the disciplinary role of debt. In both mean and median, free cash flow and leverage monotonically rise in the diversifier number of segments. These two measures are also larger for diversifiers adding multiple segments.

Panel B presents statistics for deal characteristics. Recent studies report that acquirer gain varies with the listing status of targets (i.e., listed vs. unlisted targets) and with the interaction between the target listing status and payment methods. The frequency of private targets monotonically declines in the diversifier number of segments while the opposite holds for the frequencies of subsidiary and public targets. Pure cash financing is systematically more frequent as the diversifier number of segments increases, and the opposite holds for pure equity financing. However, the differences in target listing status and deal financing are less discernible between deals adding only one and multiple segments. In both mean and median, the relative size of a deal monotonically falls in the diversifier number of segments: however, the pattern is mixed across the numbers of added segments. As a measure of competition for the target, we adopt the target industry liquidity index and calculate it following Schlingemann et al. (2002). Moeller et al. (2004) report a negative relation between acquirer gain and the index. Although the index exhibits no discernible pattern across either the diversifier number of segments or the number of added segments, the variations in the index are generally significant.

An alternative proxy for competition for targets is the presence of multiple bids. Less than $1 \%$ of the sample targets receive multiple bids as reported in the SDC. The 
literature suggests that acquirer gains vary between tender offers and mergers, and between hostile and friendly transactions. Only 3.6\% of our sample diversifiers make a tender offer, and fewer than $1 \%$ of them make a hostile bid. This is not surprising as the vast majority of our sample diversifiers acquire an unlisted target. Although for parsimony we do not include these determinants in our main analysis, untabulated results show that including them makes virtually no change to the key findings.

\section{Empirical evidence on the trade-off}

In the following subsections, we present evidence on the trade-off proposition, including refutability of the proposition. Since we use acquisitions as our empirical lab, we also attempt to reconcile our findings with the negative wealth effects of diversifying acquisitions reported in several earlier studies.

\subsection{The inverted- $U$ relation in diversifying acquisitions}

The trade-off proposition predicts a positive sign for $\hat{\beta}_{2}$ and negative sign for $\hat{\beta}_{3}$ in equation (4). Table 3 reports regression results from estimating variants of equation (4) for acquirers in diversifying acquisitions. Model (1) is the baseline model. Consistent with the prediction, both $\hat{\beta}_{2}(1.447)$ and $\hat{\beta}_{3}(-0.108)$ not only have the correct signs, but also are significant. These coefficient estimates together provide evidence that acquirer gains from diversifying acquisitions follow an inverted U-relation between the degree to which a firm operates in different industrial sectors and wealth. Specifically, the positive sign of $\hat{\beta}_{2}$ indicates that there is an important marginal benefit from diversifying. As

reflected by the negative sign of $\hat{\beta}_{3}$, however, if firms diversify to achieve some very high degree of diversification, significant costs will arise and become increasingly large to eventually more than offset the benefits. These findings imply that the benefits and 
costs of diversification vary with the degree of diversification. Specifically, the findings support the proposition that the marginal benefits of diversification exceed the costs at relatively low levels of diversification, and the opposite holds as firms diversify beyond some optimal level. Given the fluctuations in the number of diversifying deals across years observed in Panel A of Table 1 and to address the potential industry effects, model (2) incorporates year and industry fixed effects. Both $\hat{\beta}_{2}$ and $\hat{\beta}_{3}$ remain significant with the correct signs, and their magnitude also remains similar.

As mentioned in section 2, diversification motives can vary across firms. In other words, the decision to diversify is endogenous, and different firms may diversify for different reasons. When a firm announces the decision to make a diversifying acquisition, as a result, the market may be learning not only about the increase in the firm's scope, but also about the firm's type or its reason to diversify. To this extent, the results from models (1) and (2) may reflect unobservable time-invariant firm-specific factors that drive firms to diversify, rather than the outcome of the firm's existing degree of diversification $\left(d_{0}\right)$ and the amount of diversification it adds to its corporate portfolio $(\delta)$. To address this concern, we incorporate firm fixed effects.

Model (3) includes firm and year fixed effects. Notably, the adjusted $R^{2}$ of $35 \%$ in model (3) is substantially larger than those in models (1) and (2), which are less than $1 \%$. Such a large improvement in the adjusted $R^{2}$ is in line with diversification motives varying across firms and different firms gaining differently from diversification. It is also in line with the results reported in prior cross-sectional studies (see Campa and Kedia, 2002; Aggarwal and Samwick, 2003). Despite such heterogeneity, more importantly, the inverted U-relation between diversification and wealth prevails. Both $\hat{\beta}_{2}$ and $\hat{\beta}_{3}$ remain significant with the correct signs and have comparable magnitude to their counterparts in models (1) and (2). 
In model (4), we rerun model (3) by adding the control variables discussed in section 3.3. Both $\hat{\beta}_{2}$ and $\hat{\beta}_{3}$ still remain significant with the correct signs. However, it is possible that some of the firm and deal characteristics are endogenously determined.14 Importantly, these characteristics may also be correlated with the extent to which firms are diversified and/or further diversify. If firms diversify in response to an expected decline in their current activities, for example, $\delta_{i}$ and $d_{0, i}$ are likely to be correlated with Tobin's $q$ as a proxy for growth prospects. Such correlations, if present, could bias the value and significance of $\hat{\beta}_{2}$ and $\hat{\beta}_{3}$. Since both of the coefficients remain significant and have the correct signs either with or without the control variables, it is unlikely that our key results are driven by correlations among the covariates. To further address this issue, we rerun model (4) including one control variable at a time. Untabulated results show that both $\hat{\beta}_{2}$ and $\hat{\beta}_{3}$ remain significant with the correct signs regardless of the included control variable.

Although the trade-off proposition implies existence of an optimum, it is admittedly silent on what should be the value of $d_{b}$ in Figure 1 . The estimates of $\hat{\beta}_{2}$ and $\hat{\beta}_{3}$ from Table 3 imply that an optimal degree of diversification for our sample diversifying acquirers is around seven segments. We note here that this implied optimum is an average for our sample, and the optimum for an individual firm may well differ from seven. Thus, while the spirit of the trade-off proposition should be applicable for firms in general, the optimal level of diversification is likely to be firm-specific. For example, the life-cycle dynamics can create an opportunity for some firms to profitably exploit the diversification strategy, or diversify further (Bernardo and Chowdhry, 2002). Also, firms expecting a decline in the prospects of their current activities may

\footnotetext{
${ }^{14}$ For example, the choice of payment method can be constrained by the amount of free cash flow, and leverage can be chosen in response to expected growth prospects which are reflected in Tobin's $q$.
} 
find it optimal to diversify in search for new profit opportunities (Matsusaka, 2001; Gomes and Livdan, 2004). ${ }^{15}$ We address in more detail in section 4.4 how the trade-off may differ across different types of firms.

When viewed with the implied optimum of seven segments, the distribution of the numbers of segments reported in Panel B of Table 1 might appear to suggest that firms are typically under-diversified. In most deals (94.4\%), diversifiers add only one or two segments. Following a given diversifying attempt, the number of segments is concentrated at five or fewer segments (in $87.6 \%$ of the sample), which is below the implied within-sample optimal level. Because a diversifying decision is not costlessly reversible (Denis et al., 1997; Gomes and Livdan, 2004), firms may move only gradually, or partially, towards the optimal level of diversification. Plausibly, it is the irreversibility of a diversification decision that restrains firms from moving to their optimum in a given attempt.

The results for the control variables, as reported in model (4), are broadly in line with the existing literature. Though insignificantly, diversifier gains are negatively related to acquirer size and Tobin's q. Leverage does not appear to have important influence on diversifier gains. In line with the free cash flow theory, however, the coefficient of free cash flow is significantly negative. The private target dummy variable has an insignificant coefficient, indicating that diversifier gains are comparable between acquisitions of private and subsidiary companies. The significantly negative coefficient of the public target dummy is consistent with the recent studies reporting smaller acquirer gains when targets are listed firms (e.g., Moeller et al., 2004; Netter et al., 2011). The all-cash dummy variable has an insignificantly positive coefficient. The

\footnotetext{
${ }^{15}$ In this setting, firms may also find it profitable to refocus or become less diversified after a period of operating as a diversified firm. That is, firms may divest in order to move towards the optimal level of diversification. While beyond the scope of our study, divestments are a potential vehicle to achieve optimal diversification, and analyzing them should yield fruitful future research.
} 
coefficients of the all-stock dummy variable and its interaction term with the public target dummy variable have the signs consistent with the existing studies (e.g., Faccio et al., 2006) although they are insignificant at the conventional level. Relative size has a significantly positive coefficient. Given that acquirer gains are typically positive when targets are unlisted firms (e.g., Netter et al., 2011) and most of the targets in our sample are unlisted targets, a positive coefficient would be expected for relative size. Broadly in line with the extant evidence, the intensity of M\&A activities in the target's industry has a negative, albeit insignificant, impact on diversifier gains. Although all of the control variables have a coefficient sign in line with the existing literature, several of them have an insignificant coefficient. This is likely attributable to the inclusion of firm fixed effects. ${ }^{16}$ Since the specification of model (4) by definition is most robust as an empirical test of the trade-off prediction and to save space, we focus on this specification in the rest of our regression analyses. Nevertheless, the results (untabulated) for $\hat{\beta}_{2}$ and $\hat{\beta}_{3}$ based on the specifications in models (1) through (3) are similar.

In sum, the results in Table 3 provide empirical support for the trade-off prediction and evidence on the fundamental issue of when the marginal benefits of diversification exceed the costs, and vice versa. Diversification increases wealth when firms operate at low levels of diversifications. The wealth gain decreases as firms continue to diversify. If firms pursue diversification beyond the optimal level, they will hurt their shareholders. These findings can also be viewed as implying that corporate diversification can turn out a bright side as well as a dark side for shareholders.

\footnotetext{
16 When rerunning model (4) with year and industry fixed effects, untabulated results show that the coefficients of several variables, e.g., acquirer size, all-cash dummy variable as well as all-stock dummy variable and its interaction term with the public target dummy variable, become significant with their sign remaining unchanged. Similar patterns (untabulated) are also observed for the results reported in Tables 5, 7, and 9.
} 


\subsection{Unconditional estimates of diversification gains and losses}

While the evidence reported in Table 3 provides an understanding of the degree of value creation across different levels of diversification, it does not tell us about the magnitude of the gains from diversifying towards the optimal level or losses from diversifying beyond the optimal level. We now address this fundamental issue. Given the implied optimum of around seven segments for the average diversifier in our sample, we report announcement-period excess returns for four groups of diversifiers: operating in a single segment; two to three segments; four to six segments; and seven or more segments before diversifying. We also report gains separately for diversifiers that add only one segment, and two or more segments. Results are reported in Table 4.

In the full sample, as shown in the first row, single-segment diversifiers (2.49\%), diversifiers with two to three segments (1.99\%), and diversifiers with four to six segments (1.09\%) all earn a significant average announcement-period gain. Since these diversifiers are firms operating below the implied optimal number of segments, their significant gains are consistent with value creation from efficient diversification. Interestingly, diversifiers already operating in seven or more segments do not suffer a loss. Instead, they earn a marginally significant gain of $0.78 \%$ (at the $10 \%$ level): as revealed in the next two rows, however, the gain to these highly diversified firms is no longer significant when they are partitioned based on the number of new segments they add to their portfolio. Considering that very few highly diversified firms pursue further diversification and that most firms add only one or two new segments as observed in Panel B of Table 1, these results are in line with the view that firms generally diversify cautiously and stop diversifying before drawing a negative market reaction. In relation to Figure 1, these results imply that the inverted U-relation observed in Table 3 is largely depiction of contour ABD, i.e., firms generally do not diversify beyond point $d_{b}$ 
or the optimal level of diversification. Careful diversification attempts are consistent with firms trading off between the benefits and costs of diversification.

Taking account of the number of new segments added, all three groups of diversifiers operating below the implied optimal number of segments earn a significant gain when they add one new segment to their portfolio. When adding two or more segments, the gain remains significant only for single-segment diversifiers and diversifiers operating in two to three segments: the gain disappears for diversifiers operating relatively close to, though still below, the optimal level, i.e., with four to six segments. Yet, no diversifiers experience a significant loss regardless of the number of new segments added.

One prima facie implication of the trade-off proposition visible from Figure 1 is that the wealth gain from diversification $(\Delta W)$ should decrease in diversifiers' existing degree of diversification. In the full sample, diversifier gains monotonically drop in the diversifier number of segments. The $F$-statistic (4.426) rejects the null hypothesis that these gains are equal to each other. This monotonic pattern is also observed across the numbers of new segments added. When diversifiers add two or more segments, moreover, diversifier gains appear to drop faster. Overall, this pattern of wealth gains supports the trade-off implication. The median results (untabulated) are similar.

Also importantly, this pattern of gain decay extends the existing literature that reports that multi-segment firms experience a value discount relative to single-segment firms but that the discount does not become larger as the number of segments rises beyond two (see Lang and Stulz, 1994; Servaes, 1996). The evidence in Table 4 shows that the wealth effect of diversifying through acquisition is generally positive and declines in the degree to which firms already operate in different industrial sectors. 


\subsection{Vertically related and focused acquisitions}

The findings reported so far provide empirical support for the trade-off proposition. We next assess refutability of the proposition: that is, whether the findings are chance results. To do so, we rerun the analysis in Table 3 for non-diversifying deals. These deals are acquisitions in which: (i) the acquirer and target have vertically related, though different, primary segments; or (ii) the acquirer and target share the same primary segment. A lack of the intention to diversify in these deals should destroy the link between $\Delta W$ and $d_{0}$ as well as $\delta$. That is, equation (3) should not hold for nondiversifying deals. In vertically related deals, $\delta$ is not an outcome of a diversification attempt as the acquirer is a firm seeking upstream or downstream integration. In focused deals, $\delta$ is by definition zero, implying that it should be infeasible to estimate equation (4) for these deals. Because we categorize the sample deals based on the matching of the primary segments, however, $\delta$ can be greater than zero for a focused deal if the target has two or more segments and any of its non-primary segments differs from the acquirer's segment(s). Hence, the observed positive value of $\delta$ in focused deals comes from the target's peripheral business and is likely to reflect an unintended, as opposed to intended, increase in scope, thereby presenting itself as a falsification test. Results are reported in Table 5. To save space, we discuss only the key results, i.e., estimates of $\hat{\beta}_{2}$ and $\hat{\beta}_{3}$, in this and remaining analyses.

Vertically related deals are analyzed in model (1). Both $\hat{\beta}_{2}(-1.592)$ and $\hat{\beta}_{3}$ (0.073) are insignificant although their signs are opposite to the trade-off prediction. Given that acquirers and their target have different primary segments in both diversifying deals and vertically related deals, these results stand in sharp contrast to their counterparts in Table 3. Model (2) shows that both $\hat{\beta}_{2}$ and $\hat{\beta}_{3}$ for focused deals are insignificant and much smaller in magnitude than their Table 3 counterparts. Taken 
together, the inverted U-relation between the degree of diversification and wealth persistently observed in Table 3 does not describe gains from either vertically related or focused acquisitions. The relation is unique only to diversifying acquisitions. Acquirer gains from non-diversifying acquisitions are not a function of the benefits and costs of diversification that form the trade-off proposition.

Given the significant results for diversifying deals, the values of $\hat{\beta}_{2}$ and $\hat{\beta}_{3}$ for vertically related deals confirm the importance of accounting for vertical relatedness between the acquirer and target in identifying an acquisition that is a proxy for the decision to diversify. The results for focused deals suggest that additional diversification that comes from the target's non-core business(es) is unlikely to reflect a diversification attempt. The variations in result between diversifying and non-diversifying (either vertically related or focused) acquisitions also indicate that our measure of the degree of diversification is unlikely to be overly noisy.

\subsection{Firm attributes and diversification gains}

Given that firms diversify for different reasons, it is possible that firms of different attributes gain differently from diversification. Investigating this underlying implication of the endogenous nature of the decision to diversify allows us to learn how the cost-benefit trade-off in diversification might vary across types of firms.

The view that the decision to diversify reflects a profit-maximizing search for new growth opportunities (Matsusaka, 2001; Gomes and Livdan, 2004) implies that diversifying acquisitions should create wealth for firms with an anticipated decline in their current activities. At the same time, the problems associated with operating multiple businesses (e.g., bottlenecks) and ensuing costs may well materialize relatively early for such diversifiers: firms with anticipated deterioration would likely be near- 
constraint firms. If diversification is an outcome of agency problems, however, diversifiers exhibiting poor prospects should experience announcement-period losses. Similarly, the free cash flow problem implies that diversifying acquisitions by firms with large free cash flow are likely to destroy wealth. If, on the other hand, diversification is an efficient corporate strategy, free cash flow should serve to facilitate it. In this case, firms should gain from diversification in the way predicted by the trade-off even though their existing operations generate large free cash flow.

To investigate the above implications, we use Tobin's $q$ as a proxy for firms' prospects. Following the rationale discussed in prior studies (e.g., Lang et al., 1991), we define diversifiers with poor prospects, i.e., an anticipated decline in current activities, as those with the value of $q$ below one. Diversifiers have a low (high) level of free cash flow if their pre-acquisition free cash flow is below (above) the median value for the full sample. ${ }^{17}$

As shown in Panel A of Table 6, diversifiers with $q$ below one generally earn a significant average gain. Across levels of diversifiers' existing degree of diversification, the gains to these low- $q$ diversifiers by and large are comparable to those earned by diversifiers with $q$ above one. These results are consistent with diversification reflecting a profit-maximizing response to an anticipated decline in current activities. Across diversifier numbers of segments, announcement-period gains also appear to drop more quickly for low- $q$ diversifiers, becoming insignificant at the level of four to six segments and remaining insignificant thereafter, than for those with $q$ above one. Panel B reports results for sub-sampling on free cash flow. Consistent with free cash flow facilitating efficient diversification, diversifiers with a high level of free cash flow generated by

\footnotetext{
${ }^{17}$ We also rerun the tests based on the sub-sampling of diversifiers with $30 \%$ largest, $40 \%$ medium, and $30 \%$ smallest free cash flow. Results (untabulated) remain similar.
} 
their existing operations generally earn a significant gain. For both levels of free cash flow, moreover, diversifier gains monotonically decline in the diversifier number of segments as implied by the trade-off. The median results (untabulated) are similar.

To explore how the trade-off, i.e., the optimal level of diversification, might vary across firm types, we estimate equation (4) for diversifiers in the $q$ and free cash flow subsamples. Results for diversifiers with $q$ below one and above one are reported in models (1) and (2) in Table 7, respectively. In model (1), both $\hat{\beta}_{2}$ and $\hat{\beta}_{3}$ have the correct signs. However, the magnitude of the free cash flow coefficient and model constant suggests that the results are potentially affected by extreme values of this control variable. Omitting it, untabulated results show that the model (1) constant becomes much smaller and insignificant. The coefficients of other control variables, e.g., acquirer size (-1.609), also become more in line with the extant evidence. More importantly, both of $\hat{\beta}_{2}(38.956)$ and $\hat{\beta}_{3}(-3.588)$ continue to have the correct signs, and are significant at the $1 \%$ level: these estimates imply an optimal level of diversification of around five segments. The results for $\hat{\beta}_{2}$ and $\hat{\beta}_{3}$ in model (2) imply that the optimum for firms with $q$ above one is around eight segments. Omitting the free cash flow variable, untabulated results show that $\hat{\beta}_{2}$ and $\hat{\beta}_{3}$ for the relatively high- $q$ diversifiers remain significant with the same signs and virtually identical magnitude. Interestingly, diversifiers with $q$ below one and above one significantly differ only in $\hat{\beta}_{3}$, and not $\hat{\beta}_{2} \cdot{ }^{18}$ This is so either with or without the free cash flow variable included in the estimation. As a result, while the benefits of diversification are similarly available to firms regardless of their prospects, the expected costs increase at a faster rate for firms

\footnotetext{
${ }^{18}$ To test the difference in $\hat{\beta}_{2}$ and $\hat{\beta}_{3}$ between two subsamples, we stack observations from the subsamples and interact the dummy variable indicating one of the subsamples with all of the independent variables. We then estimate the regression with the year and firm fixed effects.
} 
encountering anticipated declines in their current activities, making an optimal level of diversification lower for them than for those not facing the problems.

Model (3) and (4) report estimates for the sub-sampling on free cash flow. In both models, the estimates of $\hat{\beta}_{2}$ and $\hat{\beta}_{3}$ suggest that the inverted U-relation is significant for diversifiers whether they already generate a high or low level of free cash flow. Moreover, neither $\hat{\beta}_{2}$ nor $\hat{\beta}_{3}$ is distinguishable between these two groups of diversifiers. Thus, firms gain similarly from diversification and in the way consistent with the trade-off prediction, whether their existing operations generate large or small free cash flow.

Taken together, the results in Tables 6 and 7 indicate that different firms may gain from diversification differently. Importantly, the cost-benefit trade-off, and hence, the optimal degree of diversification, can vary across firms depending on the reason(s) that drive them to diversify.

\subsection{Listing status of target firms}

Our findings that diversifying acquirers earn significant announcement-period gains deviate from several earlier studies, which report small losses to diversifying acquirers. In this section, we seek to understand this deviation. While most of the earlier studies analyze acquisitions of publicly traded targets, the vast majority of our sample targets are unlisted firms. As discussed in section 3.1, acquirer gains are likely to be a noisy measure of $\Delta W$ when acquirers have little bargaining power against their target, i.e., when their target is a publicly traded, or listed, firms. Given that acquirers have material bargaining power when their target is an unlisted firm (Officer, 2007), on the other hand, acquirer gains should adequately reflect $\Delta W$ in acquisitions of unlisted targets. If this bargaining power differential is a plausible explanation for the deviation 
of our findings from the earlier evidence, the inverted U-relation should be observable only when diversifying deals involve an unlisted target.

We first estimate gains to acquirers of publicly traded targets and acquirers of unlisted targets in diversifying acquisitions. Panel A of Table 8 shows that diversifiers acquiring a listed target suffer an insignificant average loss $(-0.30 \%)$ whereas those acquiring an unlisted target earn a significant gain $(2.35 \%) .{ }^{19}$ The insignificant loss to the listed-target acquirers largely persists across diversifier numbers of segments and does not exhibit any discernible pattern. In contrast, the significant gain to the unlistedtarget acquirers is persistent, and importantly, monotonically declines in the diversifier number of segments as predicted by the trade-off. These gain differences are indicative of acquirer gains adequately reflecting $\Delta W$ when targets are unlisted firms.

As mentioned in section 3.1, an alternative measure of $\Delta W$ is the combined gain to an acquirer and its target. If diversification creates value as our acquirer-gain results imply, we should observe significant combined gains on diversifying deals. As reported in Panel B, the combined gains are significant and persistent, although they vary indiscernibly across diversifier numbers of segments. Since a combined gain is the sum of acquirer and target gains, this indiscernible pattern may be attributable to the premium paid to targets. To the extent that the bargaining positions of acquirers and targets, and related factors such as overpayment, are deal-specific (i.e., acquirer-target pair-specific), the variation in premium may drive the combined gain to vary independently of diversifiers' existing degree of diversification. Panel C shows that target gains, a proxy for target premium, vary indiscernibly across diversifier numbers of segments. In line with the literature, target gains are large and significant. Together

\footnotetext{
${ }^{19}$ The difference between these two excess returns is also significant, consistent with the known listing effect: firms either suffer a small announcement-period loss or breakeven when acquiring a publicly listed target, but earn a significant gain when acquiring an unlisted target (e.g., Faccio et al., 2006; Netter et al., 2011). The median results (untabulated) are similar.
} 
with the small losses to listed-target acquirers observed in Panel A and significant combined gains in Panel B, large target gains are consistent with acquirers having weak bargaining power when targets are publicly traded firms.

Table 9 reports the implication of targets' listing status on the inverted Urelation between diversification and wealth. For diversifying acquisitions of listed targets, as shown in model (1), both $\hat{\beta}_{2}$ and $\hat{\beta}_{3}$ have the wrong sign although they are insignificant. The inverted U-relation is not observable when targets are publicly traded firms. Model (2) shows that, when targets are unlisted firms, both $\hat{\beta}_{2}$ (2.473) and $\hat{\beta}_{3}$ $(-0.187)$ are significant and have the signs consistent with the trade-off prediction. The contrast between the results from models (1) and (2) suggests that the difference in bargaining power of acquirers against targets between acquisitions of publicly traded targets and acquisitions of unlisted targets is a plausible explanation for the deviation of our main findings from the earlier evidence.

We also assess whether the inverted U-relation is observable when $\Delta W$ is measured as the combined gain, and whether the relation describes target gains. Model (3) reports results for combined gains. Both $\hat{\beta}_{2}$ and $\hat{\beta}_{3}$ have the wrong sign although they are insignificant. When target gain is the dependent variable, model (4) shows that both $\hat{\beta}_{2}$ and $\hat{\beta}_{3}$ are insignificant. Notably, the model's adjusted $R^{2}$ is negative, and remains negative even when omitting the control variables and all of the fixed effects, confirming that the inverted U-relation does not describe target gains. Together, the results in models (3) and (4) provide an additional indication that acquirers' bargaining power against publicly traded targets is deal-specific and does not vary with the expected benefits and costs of diversification.

To further probe the adequacy of acquirer gains as a measure of synergy, we rerun the tests in Tables 8 and 9 for vertically related and focused acquisitions. 
Untabulated results show that the listing effect is significant for both groups of nondiversifying deals: acquirers earn significant gains when targets are unlisted firms, but suffer small losses when targets are publicly traded firms. Also, combined gains are significant for both groups of non-diversifying deals, and target gains are large and significant. As with diversifying deals, if one were to make inference based on gains to acquirers of publicly traded targets, the conclusion would be that acquirers suffer small losses from non-diversifying acquisitions. Untabulated regression results show that both $\hat{\beta}_{2}$ and $\hat{\beta}_{3}$ are insignificant for both groups of non-diversifying deals regardless the target listing status, confirming refutability of the trade-off proposition despite the variation in acquirers' bargaining power.

In sum, the results reported in Tables 8 and 9 together lend support to the possibility that acquirer gains adequately reflect the wealth effect of diversifying acquisitions (i.e., $\Delta W$ ) when targets are unlisted firms. Since most of our sample deals are acquisitions of unlisted targets, the difference in acquirer bargaining power between acquisitions of publicly traded targets and unlisted targets provides a plausible explanation for the deviation of our findings from the earlier evidence.

\section{Conclusion}

Amid voluminous research, one central question about corporate diversification remains: how does diversification affect shareholder wealth? We propose that, at low levels of diversification, the marginal benefits of diversification exceed the costs yielding a wealth increase. The wealth increase becomes smaller as firms diversify further. Beyond an optimal level, the costs exceed the benefits yielding a wealth loss. This trade-off predicts an inverted U-relation between the degree of diversification and shareholder wealth. 
Using diversifying acquisitions as a proxy for diversification attempts, we find empirical support for the predicted inverted U-relation between diversification and wealth. At low levels of diversification, diversifying acquisitions significantly increase the wealth of acquirer shareholders at a decreasing rate, implying a wealth loss if firms diversify beyond the optimal level of diversification. Our results further indicate that diversification gains monotonically and significantly decline in diversifiers' existing degree of diversification. Regardless of their existing degree of diversification, however, diversifiers typically gain from their diversification attempts. Data also reveals that most diversifiers do not diversify beyond the level implied by the empirical estimates as optimal for an average diversifier in our sample. These additional findings together suggest that firms diversify cautiously and stop diversifying before the marginal benefits are offset by the costs. Consistent with the endogenous nature of the diversification decision, our analysis also suggests that the optimal level of diversification can vary across firms depending on their reasons for diversifying.

By examining how the net gain from diversification changes with the degree to which firms diversify, our study provides evidence on the fundamental issue of when the benefits of diversification are likely to exceed the costs, and vice versa. In addition, our findings taken together corroborate the recent strand of the literature, which demonstrates that diversification is an efficient corporate strategy. Accordingly, our work also offers a way to understand the large prevalence of conglomerates in the U.S. economy. 


\section{References}

Aggarwal, R.K., Samwick, A., 2003. Why do managers diversify their firms? Agency reconsidered. Journal of Finance 58, 71-118.

Amihud, Y., Lev, B., 1981. Risk reduction as a managerial motive for conglomerate mergers. Bell Journal of Economics 12, 605-617.

Bernardo, A.E., Chowdhry, B., 2002. Resources, real options, and corporate strategy. Journal of Financial Economics 63, 211-234.

Billett, M.T., Mauer, D.C., 2003. Cross-subsidies, external financing constraints, and the contribution of the internal capital market to firm value. Review of Financial Studies 16, 1167-1201.

Brown, S., Warner, J., 1980. Measuring security price performance. Journal of Financial Economics 8, 205-258.

Brown, S., Warner, J., 1985. Using daily stock returns: the case of event studies. Journal of Financial Economics 14, 3-31.

Campa, J.M., Kedia, S., 2002. Explaining the diversification discount. Journal of Finance $57,1731-1762$.

Chevalier, J., 2004. What do we know about cross-subsidization? Evidence from merging firms. Advances in Economic Analysis \& Policy 4, 1-27.

Denis, D.J., Denis, D.K., Sarin, A., 1997. Agency problems, equity ownership, and corporate diversification. Journal of Finance 52, 135-160.

Duchin, R., 2010. Cash holdings and corporate diversification. Journal of Finance 65, 955-992.

Faccio, M., McConnell, J.J., Stolin, D., 2006. Returns to acquirers of listed and unlisted targets. Journal of Financial and Quantitative Analysis 41, 197-220.

Fan, J.P.H., Goyal, V.K., 2006. On the patterns and wealth effects of vertical mergers. Journal of Business 79, 877-902.

Fan, J., Lang, L., 2000. The measurement of relatedness: An application to corporate diversification. Journal of Business 73, 629-660.

Fluck, Z., Lynch, A.W., 1999. Why do firms merge and then divest? A theory of financial synergy. Journal of Business 72, 319-346.

Fuller, K., Netter, J., Stegemoller, M., 2002. What do returns to acquiring firms tell us? Evidence from firms that make many acquisitions. Journal of Finance 57, 1763-1793. 
Gomes, J., Livdan, D. 2004. Optimal diversification: Reconciling theory and evidence. Journal of Finance 59, 507-535.

Graham, J.R., Lemmon, M.L., Wolf, J.G., 2002. Does corporate diversification destroy value? Journal of Finance 57, 695-720.

Hadlock, C.J., Ryngaert, M., Thomas, S., 2001. Corporate structure and equity offerings: Are there benefits to diversification? Journal of Business 74, 613-635.

Hann, R.N., Ogneva, M., Ozbas, O., 2013. Corporate diversification and the cost of capital. Journal of Finance 68, 1961-1999.

Hoberg, G., Phillips, G., 2010. Product market synergies and competition in mergers and acquisitions: A text-based analysis. Review of Financial Studies 23, 3773-3811.

Kahle, K.M., Walkling, R.A., 1996. The impact of industry classifications on financial research. Journal of Financial and Quantitative Analysis 31, 309-335.

Lamont, O., Polk, C., 2002. Does diversification destroy value? Evidence from industry shocks. Journal of Financial Economics 63, 51-77.

Lang, L.H.P., Stulz, R.M., 1994. Tobin's q, corporate diversification, and firm performance. Journal of Political Economy 102, 1248-1280.

Lang, L.H.P., Stulz, R.M., Walkling, R.A., 1991. A test of the free cash flow hypothesis: The case of bidder returns. Journal of Financial Economics 29, 315-335.

Lewellen, W.G., 1971. A pure financial rationale for the conglomerate merger. Journal of Finance 26, 521-537.

Maksimovic, V., Phillips, G., 2007. Conglomerate firms and internal capital markets. In Eckbo, B.E. (ed.). Handbook of Corporate Finance: Empirical Corporate Finance. Elsevier/North-Holland.

Maquieira, C.P., Megginson, W.L., Nail, L., 1998. Wealth creation versus wealth redistributions in pure stock-for-stock mergers. Journal of Financial Economics 48, 333.

March, J.G., Simon, H.A., 1958. Organizations. Wiley.

Matsusaka, J.G., 2001. Corporate diversification, value maximization, and organizational capabilities. Journal of Business 74, 409-431.

Moeller, S.B., Schlingemann, F.P., Stulz, R.M., 2004. Firm size and gains from acquisitions. Journal of Financial Economics 73, 201-228.

Morck, R., Shleifer, A., Vishny, R.W., 1990. Do managerial objectives drive bad acquisitions? Journal of Finance 45, 31-48. 
Netter, J., Stegemoller, M., Wintoki, M.B., 2011. Implications of data screens on merger and acquisition analysis: A large sample study of mergers and acquisitions from 1992 to 2009. Review of Financial Studies 24, 2316-2357.

Officer, M.S., 2007. The price of corporate liquidity: Acquisition discounts for unlisted targets. Journal of Financial Economics 83, 571-598.

Ozbas, O., Scharfstein, D.S., 2010. Evidence on the dark side of internal capital markets. Review of Financial Studies 23, 581-599.

Penrose, E., 1959. The theory of the growth of the firm. Oxford University Press.

Rajan, R., Servaes, H., Zingales, L., 2000. The cost of diversity: The diversification discount and inefficient investment. Journal of Finance 55, 35-80.

Roll, R., 1986. The hubris hypothesis in corporate takeovers. Journal of Business 59, 197-216.

Scharfstein, D.S., Stein, J.C., 2000. The dark side of internal markets: Divisional rentseeking and inefficient investment. Journal of Finance 55, 2537-2564.

Schlingemann, F.P., Stulz, R.M., Walkling, R.A., 2002. Divestitures and the liquidity of the market for corporate assets. Journal of Financial Economics 64, 117-144.

Servaes, H., 1996. The value of corporation diversification during the conglomerate merger wave. Journal of Finance 51, 1201-1225.

Shin, H.H., Stulz, R.M., 1998. Are internal capital markets efficient? Quarterly Journal of Economics 113, 531-552.

Shleifer, A., Vishny, R.W., 1989. Management entrenchment: The case of managerspecific investments. Journal of Financial Economics 25, 123-139.

Stein, J.C., 1997. Internal capital markets and the competition for corporate resources. Journal of Finance 52, 111-133.

Stein, J.C., 2003. Agency, information and corporate investment. In Constantinides, G.M., Harris, M., Stulz, R. (ed.). Handbook of the Economics of Finance. Elsevier Science B.V.

Teece, D.J., 1982. Towards an economic theory of the multiproduct firm. Journal of Economic Behavior and Organization 3, 39-63. 
Table 1

Sample distributions

Diversifying acquisitions are deals in which the acquirer and target have different primary 2-digit SIC industries where the degree of vertical relatedness between the acquirer and target primary industries is no greater than 5\%, and at least one of the target's industries differs from all of the acquirer's industries. Vertically related acquisitions are deals in which the acquirer and target have different primary 2-digit SIC industries but the degree of vertical relatedness between their primary industries is greater than $5 \%$. Focused acquisitions are deals in which the acquirer and target share the same primary 2-digit SIC industry. Panel A reports distributions of the sample acquisitions and percentage excess returns across announcement years during the sample period. Panel B reports the cumulative distribution statistics for acquirers and targets in diversifying acquisitions: the pre-acquisition number of segments for acquirers and for targets; the number of new segments added through a given acquisition; and the total number of segments acquirers have following a given acquisition.

Panel A: Distributions across sample period

\begin{tabular}{|c|c|c|c|c|c|c|c|c|}
\hline \multirow[b]{2}{*}{ Year } & \multicolumn{4}{|c|}{ Number of acquisitions } & \multicolumn{4}{|c|}{ Excess returns (\%) } \\
\hline & $\begin{array}{r}\text { Entire } \\
\text { sample }\end{array}$ & Diversifying & $\begin{array}{r}\text { Vertically } \\
\text { related } \\
\end{array}$ & Focused & $\begin{array}{r}\text { Entire } \\
\text { sample }\end{array}$ & Diversifying & $\begin{array}{r}\text { Vertically } \\
\text { related } \\
\end{array}$ & Focused \\
\hline All & 15,063 & 3,229 & 1,944 & 9,890 & 1.81 & 1.99 & 1.83 & 1.75 \\
\hline 1990 & 196 & 45 & 34 & 117 & 1.38 & 2.54 & -0.21 & 1.40 \\
\hline 1991 & 308 & 62 & 34 & 212 & 3.55 & 6.42 & 0.10 & 3.27 \\
\hline 1992 & 449 & 106 & 50 & 293 & 3.60 & 4.10 & 3.61 & 3.43 \\
\hline 1993 & 622 & 132 & 89 & 401 & 2.82 & 2.61 & 2.68 & 2.93 \\
\hline 1994 & 695 & 163 & 96 & 436 & 2.32 & 1.81 & 2.38 & 2.50 \\
\hline 1995 & 806 & 175 & 85 & 546 & 1.68 & 1.63 & 0.53 & 1.88 \\
\hline 1996 & 1,080 & 235 & 151 & 694 & 2.33 & 2.58 & 3.35 & 2.02 \\
\hline 1997 & 1,306 & 278 & 184 & 844 & 2.14 & 2.55 & 1.99 & 2.03 \\
\hline 1998 & 1,287 & 272 & 198 & 817 & 1.39 & 1.65 & 1.28 & 1.33 \\
\hline 1999 & 1,086 & 219 & 133 & 734 & 3.15 & 3.28 & 2.07 & 3.31 \\
\hline 2000 & 1,018 & 250 & 97 & 671 & 0.57 & 1.29 & 3.20 & -0.09 \\
\hline 2001 & 670 & 154 & 72 & 444 & 1.52 & 1.09 & 2.50 & 1.51 \\
\hline 2002 & 655 & 148 & 70 & 437 & 1.85 & 2.42 & 1.70 & 1.68 \\
\hline 2003 & 625 & 140 & 71 & 414 & 1.83 & 1.98 & 3.69 & 1.46 \\
\hline 2004 & 693 & 127 & 95 & 471 & 1.21 & 2.14 & 0.51 & 1.10 \\
\hline 2005 & 760 & 145 & 111 & 504 & 1.21 & 0.05 & 0.55 & 1.68 \\
\hline 2006 & 750 & 159 & 98 & 493 & 1.01 & 1.22 & 1.00 & 0.95 \\
\hline 2007 & 729 & 158 & 107 & 464 & 1.28 & 0.85 & 1.83 & 1.30 \\
\hline 2008 & 533 & 95 & 67 & 371 & 1.13 & 1.24 & 2.12 & 0.93 \\
\hline 2009 & 398 & 88 & 55 & 255 & 1.51 & 1.34 & 0.61 & 1.76 \\
\hline 2010 & 397 & 78 & 47 & 272 & 1.25 & 1.33 & 0.25 & 1.40 \\
\hline
\end{tabular}

(continued) 
Table 1 - continued

Panel B: Number of segments in diversifying acquisitions

\begin{tabular}{|c|c|c|c|c|c|c|c|c|c|c|c|c|}
\hline \multirow{2}{*}{$\begin{array}{l}\text { Number of } \\
\text { segments }\end{array}$} & \multicolumn{3}{|c|}{ Acquirer pre-acquisition } & \multicolumn{3}{|c|}{ Target pre-acquisition } & \multicolumn{3}{|c|}{ New segments added } & \multicolumn{3}{|c|}{ Acquirer post-acquisition } \\
\hline & Count & $\%$ & Cum. \% & Count & $\%$ & Cum. \% & Count & $\%$ & Cum. \% & Count & $\%$ & Cum. \% \\
\hline 1 & 1,125 & 34.8 & 34.8 & 1,706 & 52.8 & 52.8 & 2,414 & 74.8 & 74.8 & & & \\
\hline 2 & 930 & 28.8 & 63.6 & 1,019 & 31.6 & 84.4 & 634 & 19.6 & 94.4 & 875 & 27.1 & 27.1 \\
\hline 3 & 586 & 18.1 & 81.8 & 343 & 10.6 & 95.0 & 129 & 4.0 & 98.4 & 884 & 27.4 & 54.5 \\
\hline 4 & 315 & 9.8 & 91.5 & 103 & 3.2 & 98.2 & 36 & 1.1 & 99.5 & 663 & 20.5 & 75.0 \\
\hline 5 & 126 & 3.9 & 95.4 & 36 & 1.1 & 99.3 & 6 & 0.2 & 99.7 & 406 & 12.6 & 87.6 \\
\hline 6 & 54 & 1.7 & 97.1 & 9 & 0.3 & 99.6 & 5 & 0.2 & 99.8 & 179 & 5.5 & 93.1 \\
\hline 7 & 42 & 1.3 & 98.4 & 7 & 0.2 & 99.8 & 4 & 0.1 & 100.0 & 93 & 2.9 & 96.0 \\
\hline 8 & 14 & 0.4 & 98.9 & 4 & 0.1 & 99.9 & 0 & 0.0 & 100.0 & 53 & 1.6 & 97.6 \\
\hline 9 & 20 & 0.6 & 99.5 & 1 & 0.0 & 100.0 & 0 & 0.0 & 100.0 & 30 & 0.9 & 98.6 \\
\hline 10 & 16 & 0.5 & 100.0 & 0 & 0.0 & 100.0 & 1 & 0.0 & 100.0 & 13 & 0.4 & 99.0 \\
\hline 11 & 1 & 0.0 & 100.0 & 1 & 0.0 & 100.0 & & & & 18 & 0.6 & 99.5 \\
\hline 12 & & & & & & & & & & 9 & 0.3 & 99.8 \\
\hline 13 & & & & & & & & & & 0 & 0.0 & 99.8 \\
\hline 14 & & & & & & & & & & 5 & 0.2 & 100.0 \\
\hline 15 & & & & & & & & & & 0 & 0.0 & 100.0 \\
\hline 16 & & & & & & & & & & 1 & 0.0 & 100.0 \\
\hline Total count & 3,229 & & & 3,229 & & & 3,229 & & & 3,229 & & \\
\hline
\end{tabular}




\section{Table 2 \\ Diversifier and deal characteristics}

The sample consists of the 3,229 diversifying acquisitions. The sample deals are divided into groups of: diversifier pre-acquisition numbers of segments $\left(d_{0}\right)$, i.e., single segment, 2 to 4 segments, and 5 or more segments; and into groups of numbers of new segments that are added per deal to the diversifier's corporate portfolio $(\delta)$, i.e., 1 , and 2 or more segments. Diversifier and deal characteristics are reported in Panels A and B, respectively. Total assets are book total assets for year ending before the announcement date (day 0). A proxy for Tobin's $q$ is firm market value divided by book total assets, where firm market value is book total assets minus book value of common equity plus market cap. Market cap is the market value of common equity observed 11 days before day 0 . Free cash flow is the ratio of earnings before interests, taxes and depreciation minus capital expenditure to firm market value. Leverage is book total assets minus book value of common equity scaled by firm market value. Relative size is the ratio of transaction value (excluding fees and expenses) to market cap of the diversifier. The target industry liquidity index is calculated following Schlingemann et al. (2002): the value of all corporate control transactions made within the target's 2-digit SIC code industry and year of acquisition divided by the total book value of assets of all firms in the same industry and year. The statistics reported for target listing status and payment methods are proportions. Private, subsidiary and public targets are, respectively, independent private companies or assets, subsidiaries of a listed parent, and publicly traded companies. All cash (all stock) deals are deals financed with 100\% cash (common stock). ***, **, and * denote the means, medians (in italics) or proportions being significantly different across diversifier pre-acquisition numbers of segments or numbers of new segments added, at the $1 \%, 5 \%$ and $10 \%$ levels, respectively.

\begin{tabular}{|c|c|c|c|c|c|c|}
\hline & \multirow[b]{2}{*}{ All deals } & \multicolumn{3}{|c|}{ Diversifier no. of segments } & \multicolumn{2}{|c|}{ No. of added segments } \\
\hline & & $d_{0}=1$ & $2 \leq d_{0} \leq 4$ & $5 \leq d_{0}$ & $\delta=1$ & $2 \leq \delta$ \\
\hline \multicolumn{7}{|c|}{ Panel A: Diversifier characteristics } \\
\hline \multirow[t]{2}{*}{ Total assets ( $\$$ mil) } & 2,359 & 1,458 & 1,623 & $11,010^{* * *}$ & 1,688 & $4,347^{* * *}$ \\
\hline & 138 & 54 & 172 & $1,024^{* * *}$ & 125 & $193^{* * *}$ \\
\hline \multirow[t]{2}{*}{ Tobin's $q$} & 5.68 & 8.70 & 4.40 & $1.81^{* * *}$ & 5.97 & $4.82^{* * *}$ \\
\hline & 1.93 & 2.13 & 1.89 & $1.55^{* * *}$ & 1.98 & $1.81^{* * *}$ \\
\hline \multirow[t]{2}{*}{ Free cash flow (\%) } & 0.44 & -0.67 & 0.82 & $2.50^{* * *}$ & 0.34 & 0.75 \\
\hline & 1.83 & 1.01 & 2.00 & $2.84^{* * *}$ & 1.70 & $2.10^{* * *}$ \\
\hline \multirow[t]{2}{*}{ Leverage (\%) } & 25.49 & 28.85 & 27.91 & $40.20^{* * *}$ & 27.60 & $31.72^{* * *}$ \\
\hline & 19.97 & 24.17 & 23.39 & $38.05^{* * *}$ & 22.74 & $27.83^{* * *}$ \\
\hline \multicolumn{7}{|c|}{ Panel B: Deal characteristics } \\
\hline Private target $(\%)$ & 54.17 & 61.42 & 52.38 & $36.26^{* * *}$ & 56.84 & $46.26^{* * *}$ \\
\hline Subsidiary target (\%) & 32.12 & 28.62 & 33.21 & $39.19^{* * *}$ & 32.56 & 30.80 \\
\hline Public target (\%) & 13.72 & 9.96 & 14.42 & $24.54^{* * *}$ & 10.60 & $22.94^{* * *}$ \\
\hline All cash (\%) & 27.47 & 23.02 & 28.40 & $39.56^{* * *}$ & 25.93 & $32.02^{* * *}$ \\
\hline All stock (\%) & 14.15 & 17.69 & 13.05 & $6.96^{* * *}$ & 14.46 & 13.25 \\
\hline \multirow[t]{2}{*}{ Relative size (\%) } & 30.22 & 51.73 & 19.59 & $12.88^{* * *}$ & 32.90 & $22.28^{*}$ \\
\hline & 6.13 & 8.12 & 5.68 & $3.60^{* * *}$ & 5.93 & $7.08^{* *}$ \\
\hline \multirow[t]{2}{*}{ Target industry liquidity } & 0.107 & 0.097 & 0.113 & 0.105 & 0.101 & $0.124^{* * *}$ \\
\hline & 0.054 & 0.057 & 0.055 & $0.047^{* *}$ & 0.058 & $0.049^{* * *}$ \\
\hline
\end{tabular}




\section{Table 3 \\ Regression analysis of gains to diversifying acquirers}

Results from estimating variants of equation (4) for acquirers in diversifying acquisitions are reported. In all models, the dependent variable is acquirer announcement-period gain. $\delta_{i}$ is the number of new segments added through an acquisition by acquirer $i$, and $d_{0, i}$ the acquirer's pre-acquisition number of segments. Acquirer size is book total assets. The private target and public target dummy variables are $1(0)$ if the target is an independent private target, and publicly traded target, respectively (otherwise). The all cash and all stock dummy variables are 1(0) if the deal is financed purely, respectively, with cash and with stock (otherwise). The industry fixed effects represent acquirers' primary 2-digit SIC industries. All other explanatory variables are defined as in Table 2 . In parentheses is $p$-value based on the White standard errors that are robust to clustering at the acquirer level.

\begin{tabular}{|c|c|c|c|c|}
\hline Explanatory variables & 1 & 2 & 3 & 4 \\
\hline \multirow[t]{2}{*}{$\delta_{i}$} & 1.447 & 1.658 & 1.894 & 2.215 \\
\hline & $(0.001)$ & $(0.000)$ & $(0.007)$ & $(0.003)$ \\
\hline \multirow[t]{2}{*}{$\left(2 d_{0, i} \delta_{i}+\delta_{i}^{2}\right)$} & -0.108 & -0.118 & -0.133 & -0.157 \\
\hline & $(0.000)$ & $(0.000)$ & $(0.012)$ & $(0.008)$ \\
\hline \multirow[t]{2}{*}{ Acquirer size } & & & & -0.369 \\
\hline & & & & $(0.592)$ \\
\hline \multirow[t]{2}{*}{ Tobin's $q$} & & & & -0.859 \\
\hline & & & & $(0.396)$ \\
\hline \multirow[t]{2}{*}{ Leverage } & & & & -0.263 \\
\hline & & & & $(0.945)$ \\
\hline \multirow[t]{2}{*}{ Free cash flow } & & & & -15.447 \\
\hline & & & & $(0.003)$ \\
\hline \multirow[t]{2}{*}{ Private target } & & & & 0.323 \\
\hline & & & & $(0.591)$ \\
\hline \multirow[t]{2}{*}{ Public target } & & & & -1.585 \\
\hline & & & & $(0.021)$ \\
\hline \multirow[t]{2}{*}{ All cash } & & & & 0.760 \\
\hline & & & & $(0.158)$ \\
\hline \multirow[t]{2}{*}{ All stock } & & & & 1.839 \\
\hline & & & & $(0.151)$ \\
\hline \multirow[t]{2}{*}{ Public target $\times$ all stock } & & & & -2.568 \\
\hline & & & & $(0.127)$ \\
\hline \multirow[t]{2}{*}{ Relative size } & & & & 0.469 \\
\hline & & & & $(0.044)$ \\
\hline \multirow[t]{2}{*}{ Target industry liquidity } & & & & -0.233 \\
\hline & & & & $(0.323)$ \\
\hline \multirow[t]{2}{*}{ Constant } & 1.007 & 2.127 & 0.012 & 2.559 \\
\hline & $(0.025)$ & $(0.180)$ & $(0.997)$ & $(0.590)$ \\
\hline Year fixed effects & & yes & yes & yes \\
\hline Industry fixed effects & & yes & & \\
\hline Firm fixed effects & & & yes & yes \\
\hline$R^{2}(\%)$ & 0.29 & 0.93 & 35.21 & 36.39 \\
\hline No. of usable observations & 3,229 & 3,229 & 3,229 & 3,229 \\
\hline
\end{tabular}




\section{Table 4 \\ Announcement-period gains to diversifying acquirers}

Average percentage announcement-period gains to acquirers in diversifying acquisitions (diversifiers) are reported. Deals are divided into groups based on diversifier pre-acquisition number of segments $\left(d_{0}\right)$ : single-segment; 2 to 3 segments; 4 to 6 segments; and 7 or more segments. For each group, results are also reported by the number of new segments added through a given acquisition $(\delta): 1$; and 2 or more segments. The $F$-statistics allowing for unequal variances are reported for the null hypothesis of acquirer gain being equal across acquirer groups. In parentheses is $p$-value. In brackets is sample size.

\begin{tabular}{|c|c|c|c|c|c|}
\hline & \multicolumn{4}{|c|}{ Diversifier number of segments } & \multirow[b]{2}{*}{$F$-statistic } \\
\hline & $d_{0}=1$ & $2 \leq d_{0} \leq 3$ & $4 \leq d_{0} \leq 6$ & $7 \leq d_{0}$ & \\
\hline \multirow[t]{3}{*}{ All firms } & 2.49 & 1.99 & 1.09 & 0.78 & 4.426 \\
\hline & $(0.000)$ & $(0.000)$ & $(0.002)$ & $(0.086)$ & $(0.004)$ \\
\hline & {$[1,125]$} & {$[1,516]$} & [495] & [93] & \\
\hline \multirow[t]{3}{*}{$\delta=1$} & 2.18 & 1.73 & 1.52 & 0.80 & 1.635 \\
\hline & $(0.000)$ & $(0.000)$ & $(0.000)$ & $(0.119)$ & $(0.181)$ \\
\hline & [875] & {$[1,122]$} & [362] & [55] & \\
\hline \multirow[t]{3}{*}{$2 \leq \delta$} & 3.57 & 2.70 & -0.10 & 0.74 & 5.723 \\
\hline & $(0.000)$ & $(0.000)$ & $(0.880)$ & $(0.379)$ & $(0.001)$ \\
\hline & [250] & [394] & [133] & [38] & \\
\hline
\end{tabular}


Table 5

Regression analysis of gains to non-diversifying acquirers

Results from estimating a variant of equation (4) for acquirers in non-diversifying acquisitions are reported. The dependent variable is acquirer announcement-period gain. All explanatory variables are defined as in Tables 2 and 3. Models (1) and (2) report results for acquirers in vertically related and focused acquisitions, respectively. In parentheses is $p$-value based on the White standard errors that are robust to clustering at the acquirer level.

\begin{tabular}{|c|c|c|}
\hline & Vertically related & Focused \\
\hline Explanatory variables & 1 & 2 \\
\hline \multirow[t]{2}{*}{$\delta_{i}$} & -1.592 & 0.732 \\
\hline & $(0.118)$ & $(0.181)$ \\
\hline \multirow[t]{2}{*}{$\left(2 d_{0, i} \delta_{i}+\delta_{i}^{2}\right)$} & 0.073 & -0.074 \\
\hline & $(0.440)$ & $(0.226)$ \\
\hline \multirow[t]{2}{*}{ Acquirer size } & -0.996 & -1.570 \\
\hline & $(0.217)$ & $(0.000)$ \\
\hline \multirow[t]{2}{*}{ Tobin's $q$} & -1.113 & -1.169 \\
\hline & $(0.369)$ & $(0.011)$ \\
\hline \multirow[t]{2}{*}{ Leverage } & 1.586 & 0.522 \\
\hline & $(0.722)$ & $(0.741)$ \\
\hline \multirow[t]{2}{*}{ Free cash flow } & -34.076 & -4.307 \\
\hline & $(0.030)$ & $(0.212)$ \\
\hline \multirow[t]{2}{*}{ Private target } & -0.602 & 0.204 \\
\hline & $(0.337)$ & $(0.496)$ \\
\hline \multirow[t]{2}{*}{ Public target } & -1.454 & -2.388 \\
\hline & $(0.140)$ & $(0.000)$ \\
\hline \multirow[t]{2}{*}{ All cash } & -0.225 & 0.377 \\
\hline & $(0.685)$ & $(0.145)$ \\
\hline \multirow[t]{2}{*}{ All stock } & 0.327 & 0.350 \\
\hline & $(0.801)$ & $(0.610)$ \\
\hline \multirow[t]{2}{*}{ Public target $\times$ all stock } & 0.800 & -3.176 \\
\hline & $(0.746)$ & $(0.001)$ \\
\hline \multirow[t]{2}{*}{ Relative size } & 0.195 & 0.363 \\
\hline & $(0.368)$ & $(0.001)$ \\
\hline \multirow[t]{2}{*}{ Target industry liquidity } & 0.568 & 0.241 \\
\hline & $(0.099)$ & $(0.256)$ \\
\hline \multirow[t]{2}{*}{ Constant } & 10.656 & 13.774 \\
\hline & $(0.021)$ & $(0.000)$ \\
\hline Year fixed effects & yes & yes \\
\hline Firm fixed effects & yes & yes \\
\hline$R^{2}(\%)$ & 49.51 & 21.26 \\
\hline No. of usable observations & 1,944 & 9,890 \\
\hline
\end{tabular}




\section{Table 6}

\section{Announcement-period gains to different groups of diversifying acquirers}

Average percentage announcement-period gains to acquirers in diversifying acquisitions (diversifiers) are reported. In Panel A, deals are partitioned into two subsamples with the value of a proxy for diversifier Tobin's $q$ below one and above one. In Panel B, deals are partitioned into two subsamples with the level of diversifier free cash flow above (high-cash) and below (low-cash) the sample median. For both panels, differences in acquirer gain between two subsamples (i.e., $q<1$ vs. $q>1$, and high-cash vs. low-cash) are also reported. For each subsample, deals are also divided into groups based on diversifier pre-acquisition number of segments $\left(d_{0}\right)$ : single-segment; 2 to 3 segments; 4 to 6 segments; and 7 or more segments. Significance of differences between two subsamples is based on an independent-samples $t$-test allowing for unequal variances. The $F$-statistics allowing for unequal variances are reported for the null hypothesis of acquirer gain being equal across diversifier numbers of segments. In parentheses is $p$ value. In brackets is sample size.

\begin{tabular}{|c|c|c|c|c|c|c|}
\hline & \multirow[b]{2}{*}{ All } & \multicolumn{5}{|c|}{ Diversifier number of segments } \\
\hline & & $d_{0}=1$ & $2 \leq d_{0} \leq 3$ & $4 \leq d_{0} \leq 6$ & $7 \leq d_{0}$ & $F$-statistic \\
\hline \multicolumn{7}{|c|}{ Panel A: Sub-sampling on Tobin's q } \\
\hline \multirow[t]{3}{*}{$q<1$} & 4.18 & 2.76 & 6.35 & 1.33 & -1.72 & 2.782 \\
\hline & $(0.000)$ & $(0.070)$ & $(0.000)$ & $(0.481)$ & $(0.524)$ & $(0.058)$ \\
\hline & {$[254]$} & [88] & [123] & [37] & [6] & \\
\hline \multirow[t]{3}{*}{$q>1$} & 1.80 & 2.47 & 1.60 & 1.07 & 0.95 & 3.376 \\
\hline & $(0.000)$ & $(0.000)$ & $(0.000)$ & $(0.003)$ & $(0.038)$ & $(0.018)$ \\
\hline & {$[2,975]$} & {$[1,037]$} & {$[1,393]$} & [458] & [87] & \\
\hline \multicolumn{7}{|l|}{ Difference: } \\
\hline \multirow[t]{2}{*}{$q<1$ vs. $q>1$} & 2.38 & 0.29 & 4.75 & 0.26 & -2.67 & \\
\hline & $(0.024)$ & $(0.849)$ & $(0.008)$ & $(0.889)$ & $(0.301)$ & \\
\hline \multicolumn{7}{|c|}{ Panel B: Sub-sampling on free cash flow levels } \\
\hline \multirow[t]{3}{*}{ High-cash } & 1.49 & 1.92 & 1.67 & 0.57 & 0.76 & 2.814 \\
\hline & $(0.000)$ & $(0.000)$ & $(0.000)$ & $(0.081)$ & $(0.243)$ & $(0.040)$ \\
\hline & {$[1,615]$} & {$[460]$} & [783] & [318] & [54] & \\
\hline \multirow[t]{3}{*}{ Low-cash } & 2.49 & 2.88 & 2.32 & 2.01 & 0.80 & 2.443 \\
\hline & $(0.000)$ & $(0.000)$ & $(0.000)$ & $(0.012)$ & $(0.195)$ & $(0.065)$ \\
\hline \multirow{2}{*}{\multicolumn{7}{|c|}{ Difference: }} \\
\hline & & & & & & \\
\hline \multirow[t]{2}{*}{ High-cash vs. low-cash } & -0.99 & -0.97 & -0.66 & -1.45 & 0.04 & \\
\hline & $(0.010)$ & $(0.160)$ & $(0.266)$ & $(0.092)$ & $(0.963)$ & \\
\hline
\end{tabular}




\section{Table 7}

\section{Regression analysis of gains to different groups of diversifying acquirers}

Results from estimating a variant of equation (4) for acquirers in diversifying acquisitions (diversifiers) are reported. The dependent variable is acquirer announcement-period gain. All explanatory variables are defined as in Tables 2 and 3. Models (1) and (2) report results for diversifiers with the value of a proxy for Tobin's $q$ below one and above one, respectively. Models (3) and (4) report results for diversifiers with a free cash flow level above (high-cash) and below (low-cash) the sample median, respectively. In parentheses is $p$-value based on the White standard errors that are robust to clustering at the acquirer level.

\begin{tabular}{|c|c|c|c|c|}
\hline & $q<1$ & $q>1$ & High-cash & Low-cash \\
\hline Explanatory variables & 1 & 2 & 3 & 4 \\
\hline \multirow[t]{2}{*}{$\delta_{i}$} & 41.566 & 1.927 & 1.759 & 2.385 \\
\hline & $(0.000)$ & $(0.003)$ & $(0.048)$ & $(0.036)$ \\
\hline \multirow[t]{2}{*}{$\left(2 d_{0, i} \delta_{i}+\delta_{i}^{2}\right)$} & -0.499 & -0.121 & -0.104 & -0.144 \\
\hline & $(0.343)$ & $(0.011)$ & $(0.077)$ & $(0.037)$ \\
\hline \multirow[t]{2}{*}{ Acquirer size } & 65.544 & -0.468 & -0.960 & 0.653 \\
\hline & $(0.000)$ & $(0.471)$ & $(0.252)$ & $(0.649)$ \\
\hline \multirow[t]{2}{*}{ Tobin's $q$} & -20.497 & -1.542 & 1.989 & -0.782 \\
\hline & $(0.016)$ & $(0.138)$ & $(0.264)$ & $(0.598)$ \\
\hline \multirow[t]{2}{*}{ Leverage } & 56.734 & -3.516 & 4.944 & -0.673 \\
\hline & $(0.000)$ & $(0.351)$ & $(0.377)$ & $(0.905)$ \\
\hline \multirow[t]{2}{*}{ Free cash flow } & -457.040 & -11.983 & 34.576 & -15.078 \\
\hline & $(0.000)$ & $(0.252)$ & $(0.224)$ & $(0.035)$ \\
\hline \multirow[t]{2}{*}{ Private target } & -1.848 & 0.651 & 0.038 & 0.402 \\
\hline & $(0.586)$ & $(0.253)$ & $(0.956)$ & $(0.741)$ \\
\hline \multirow[t]{2}{*}{ Public target } & -0.245 & -1.636 & -0.954 & -4.193 \\
\hline & $(0.962)$ & $(0.021)$ & $(0.345)$ & $(0.005)$ \\
\hline \multirow[t]{2}{*}{ All cash } & -0.060 & 0.690 & 0.395 & 0.830 \\
\hline & $(0.987)$ & $(0.196)$ & $(0.516)$ & $(0.508)$ \\
\hline \multirow[t]{2}{*}{ All stock } & -11.105 & 1.185 & 1.190 & 0.631 \\
\hline & $(0.000)$ & $(0.334)$ & $(0.534)$ & $(0.708)$ \\
\hline \multirow[t]{2}{*}{ Public target $\times$ all stock } & 15.154 & -0.852 & -5.364 & 1.834 \\
\hline & $(0.002)$ & $(0.590)$ & $(0.029)$ & $(0.450)$ \\
\hline \multirow[t]{2}{*}{ Relative size } & -0.158 & 0.508 & 0.577 & -0.024 \\
\hline & $(0.917)$ & $(0.033)$ & $(0.032)$ & $(0.956)$ \\
\hline \multirow[t]{2}{*}{ Target industry liquidity } & 19.134 & -0.049 & -0.048 & -0.011 \\
\hline & $(0.000)$ & $(0.832)$ & $(0.874)$ & $(0.981)$ \\
\hline \multirow[t]{2}{*}{ Constant } & -538.194 & 8.171 & -1.189 & -2.550 \\
\hline & $(0.000)$ & $(0.068)$ & $(0.870)$ & $(0.758)$ \\
\hline Year fixed effects & yes & yes & yes & yes \\
\hline Firm fixed effects & yes & yes & yes & yes \\
\hline$R^{2}(\%)$ & 85.65 & 37.89 & 39.25 & 34.78 \\
\hline No. of usable observations & 254 & 2,975 & 1,615 & 1,614 \\
\hline
\end{tabular}




\section{Table 8}

\section{Target listing status and announcement-period gains in diversifying acquisitions}

Average percentage announcement-period gains to firms involved in diversifying acquisitions are reported. In Panel A, acquirer gains are reported, and acquirers (diversifiers) are partitioned into subsamples by the listing status of their target - i.e., publicly listed or unlisted target. Panel A also reports differences in acquirer gain between acquirers of listed targets and unlisted targets. Panels B and C report combined gains to pairs of acquirer and target, and gains to targets, respectively. Combined gain is calculated as a weighted average of the gains to the acquirer and target with the weights being the market cap of the acquirer and target observed 11 days before the announcement date. For each panel and subsample, deals are divided into groups based on diversifier pre-acquisition number of segments $\left(d_{0}\right)$ : single-segment; 2 to 3 segments; 4 to 6 segments; and 7 or more segments. Significance of differences between two subsamples is based on an independent-samples $t$-test allowing for unequal variances. The $F$-statistics allowing for unequal variances are reported for the null hypothesis of acquirer announcement-period gain being equal across diversifier numbers of segments. In parentheses is $p$-value. In brackets is sample size.

\begin{tabular}{|c|c|c|c|c|c|c|}
\hline & \multirow[b]{2}{*}{ All } & \multicolumn{5}{|c|}{ Diversifier number of segments } \\
\hline & & $d_{0}=1$ & $2 \leq d_{0} \leq 3$ & $4 \leq d_{0} \leq 6$ & $7 \leq d_{0}$ & $F$-statistic \\
\hline \multicolumn{7}{|l|}{ Panel A: Acquirer gains } \\
\hline \multirow[t]{3}{*}{ Listed targets } & -0.30 & -0.34 & -0.12 & -0.73 & 0.17 & 0.252 \\
\hline & $(0.464)$ & $(0.711)$ & $(0.851)$ & $(0.368)$ & $(0.813)$ & $(0.860)$ \\
\hline & [443] & [112] & [195] & {$[104]$} & [32] & \\
\hline \multirow[t]{3}{*}{ Unlisted targets } & 2.35 & 2.80 & 2.30 & 1.57 & 1.10 & 2.913 \\
\hline & $(0.000)$ & $(0.000)$ & $(0.000)$ & $(0.000)$ & $(0.063)$ & $(0.035)$ \\
\hline & {$[2,786]$} & {$[1,013]$} & {$[1,321]$} & [391] & [61] & \\
\hline \multicolumn{7}{|l|}{ Difference: } \\
\hline \multirow[t]{2}{*}{ Listed vs. unlisted targets } & -2.65 & -3.14 & -2.42 & -2.30 & -0.93 & \\
\hline & $(0.000)$ & $(0.008)$ & $(0.001)$ & $(0.008)$ & $(0.325)$ & \\
\hline \multicolumn{7}{|l|}{ Panel B: Combined gains } \\
\hline \multirow[t]{3}{*}{ Listed targets } & 1.65 & 1.67 & 1.71 & 1.37 & 2.04 & 0.130 \\
\hline & $(0.000)$ & $(0.059)$ & $(0.005)$ & $(0.042)$ & $(0.023)$ & $(0.942)$ \\
\hline & [443] & [112] & [195] & [104] & [32] & \\
\hline \multicolumn{7}{|l|}{ Panel C: Target gains } \\
\hline \multirow[t]{3}{*}{ Listed targets } & 22.46 & 17.79 & 23.38 & 26.31 & 20.64 & 2.361 \\
\hline & $(0.000)$ & $(0.000)$ & $(0.000)$ & $(0.000)$ & $(0.000)$ & $(0.074)$ \\
\hline & [443] & [112] & [195] & [104] & [32] & \\
\hline
\end{tabular}




\section{Table 9}

\section{Regression analysis of gains in diversifying acquisitions}

Results from estimating a variant of equation (4) for firms involved in diversifying acquisitions are reported. Models (1) and (2) report results for acquirers of listed targets and acquirers of unlisted targets, respectively, and the dependent variable is acquirer announcement-period gain. In models (3) and (4), the dependent variable is combined gain to a pair of acquirer and target, and target gain, respectively. All explanatory variables are defined as in Tables 2 and 3. In parentheses is $p$-value based on the White standard errors that are robust to clustering at the acquirer level.

\begin{tabular}{|c|c|c|c|c|}
\hline \multirow[b]{3}{*}{ Explanatory variables } & \multicolumn{2}{|c|}{ Acquirer gain } & \multirow[b]{2}{*}{$\begin{array}{r}\text { Combined } \\
\text { gain }\end{array}$} & \multirow[b]{2}{*}{$\begin{array}{r}\text { Target } \\
\text { gain }\end{array}$} \\
\hline & $\begin{array}{l}\text { Listed } \\
\text { targets }\end{array}$ & $\begin{array}{r}\text { Unlisted } \\
\text { targets }\end{array}$ & & \\
\hline & 1 & 2 & 3 & 4 \\
\hline \multirow[t]{2}{*}{$\delta_{i}$} & -1.841 & 2.473 & -0.588 & 7.382 \\
\hline & $(0.110)$ & $(0.004)$ & $(0.581)$ & $(0.173)$ \\
\hline \multirow[t]{2}{*}{$\left(2 d_{0, i} \delta_{i}+\delta_{i}^{2}\right)$} & 0.067 & -0.187 & 0.018 & -0.466 \\
\hline & $(0.220)$ & $(0.001)$ & $(0.729)$ & $(0.164)$ \\
\hline \multirow[t]{2}{*}{ Acquirer size } & 3.035 & -0.571 & 2.016 & 1.011 \\
\hline & $(0.124)$ & $(0.479)$ & $(0.233)$ & $(0.869)$ \\
\hline \multirow[t]{2}{*}{ Tobin's $q$} & 8.637 & -1.474 & 6.116 & -11.582 \\
\hline & $(0.031)$ & $(0.182)$ & $(0.039)$ & $(0.257)$ \\
\hline \multirow[t]{2}{*}{ Leverage } & 31.308 & -5.020 & 22.010 & -37.734 \\
\hline & $(0.023)$ & $(0.226)$ & $(0.021)$ & $(0.344)$ \\
\hline \multirow[t]{2}{*}{ Free cash flow } & 31.180 & -16.189 & 21.745 & -137.327 \\
\hline & (0.039) & $(0.004)$ & $(0.041)$ & (0.017) \\
\hline \multirow[t]{2}{*}{ All cash } & 1.738 & 0.391 & 0.896 & 6.527 \\
\hline & $(0.127)$ & $(0.521)$ & $(0.400)$ & $(0.403)$ \\
\hline \multirow[t]{2}{*}{ All stock } & 1.509 & 2.420 & 2.173 & 4.494 \\
\hline & $(0.512)$ & $(0.086)$ & $(0.315)$ & $(0.689)$ \\
\hline \multirow[t]{2}{*}{ Relative size } & -0.260 & 0.791 & 0.282 & -0.848 \\
\hline & $(0.632)$ & $(0.005)$ & $(0.585)$ & $(0.676)$ \\
\hline \multirow[t]{2}{*}{ Target industry liquidity } & -1.346 & -0.084 & -1.057 & -0.646 \\
\hline & $(0.021)$ & $(0.753)$ & $(0.019)$ & $(0.832)$ \\
\hline \multirow[t]{2}{*}{ Constant } & -41.780 & 3.908 & -28.810 & 17.501 \\
\hline & $(0.025)$ & $(0.477)$ & $(0.047)$ & $(0.714)$ \\
\hline Year fixed effects & yes & yes & yes & yes \\
\hline Firm fixed effects & yes & yes & yes & yes \\
\hline$R^{2}(\%)$ & 42.79 & 35.44 & 51.55 & -5.79 \\
\hline No. of usable observations & 443 & 2,786 & 443 & 443 \\
\hline
\end{tabular}


Figure 1

An inverted U-relation between degree of diversification and shareholder wealth

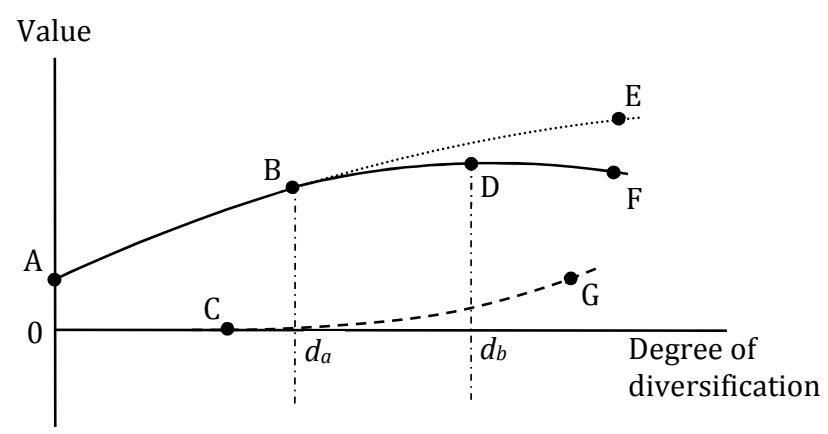




\section{Appendix}

\section{Table A.I}

\section{Announcement-period gains to diversifying acquirers using Herfindahl index}

Average percentage announcement-period gains to acquirers in diversifying acquisitions (diversifiers) are reported. Deals are divided into groups based on diversifier pre-acquisition asset-based Herfindahl index $(H)$ : $H=1 ; 0.8<H<1 ; 0.6<H<0.8 ; 0.4<H<0.6$; and $0.0<H<0.4$. For each group, results are also reported by the number of new segments added through a given acquisition $(\delta): 1$; and 2 or more segments. The $F$-statistics allowing for unequal variances are reported for the null hypothesis of acquirer gain being equal across acquirer groups. In parentheses is $p$-value. In brackets is sample size.

\begin{tabular}{|c|c|c|c|c|c|c|}
\hline & \multicolumn{5}{|c|}{ Diversifier $H$ Index } & \multirow[b]{2}{*}{$F$-statistic } \\
\hline & $H=1$ & $\begin{array}{r}0.8< \\
H \\
<1 \\
\end{array}$ & $\begin{array}{r}0.6< \\
H \\
<0.8 \\
\end{array}$ & $\begin{array}{r}0.4< \\
H \\
<0.6 \\
\end{array}$ & $\begin{array}{r}0.0< \\
H \\
<0.4 \\
\end{array}$ & \\
\hline All firms & $\begin{array}{r}2.57 \\
(0.000) \\
{[1,717]}\end{array}$ & $\begin{array}{r}1.80 \\
(0.007) \\
{[171]} \\
\end{array}$ & $\begin{array}{r}1.78 \\
(0.002) \\
{[331]} \\
\end{array}$ & $\begin{array}{r}1.47 \\
(0.000) \\
{[627]} \\
\end{array}$ & $\begin{array}{r}0.48 \\
(0.173) \\
{[383]} \\
\end{array}$ & $\begin{array}{r}5.311 \\
(0.000)\end{array}$ \\
\hline$\delta=1$ & $\begin{array}{r}2.32 \\
(0.000) \\
{[1,364]}\end{array}$ & $\begin{array}{r}1.85 \\
(0.023) \\
{[122]}\end{array}$ & $\begin{array}{r}1.33 \\
(0.068) \\
{[242]}\end{array}$ & $\begin{array}{r}1.33 \\
(0.001) \\
{[421]}\end{array}$ & $\begin{array}{r}0.68 \\
(0.064) \\
{[265]}\end{array}$ & $\begin{array}{r}2.866 \\
(0.023)\end{array}$ \\
\hline $2 \leq \delta$ & $\begin{array}{r}3.56 \\
(0.000) \\
{[353]}\end{array}$ & $\begin{array}{r}1.68 \\
(0.162) \\
{[49]}\end{array}$ & $\begin{array}{r}3.01 \\
(0.001) \\
{[89]}\end{array}$ & $\begin{array}{r}1.77 \\
(0.030) \\
{[206]}\end{array}$ & $\begin{array}{r}0.02 \\
(0.984) \\
{[118]}\end{array}$ & $\begin{array}{r}3.295 \\
(0.012)\end{array}$ \\
\hline
\end{tabular}

